\title{
Wnt signalling and cancer stem cells
}

\author{
Jesús Espada $^{1}$, Moisés B. Calvo ${ }^{2}$, Silvia Díaz-Prado ${ }^{3}$, Vanessa Medina ${ }^{4}$ \\ ${ }^{1}$ Biomedical Research Institute "Alberto Sols" (CSIC-UAM), Madrid, Spain \\ ${ }^{2}$ Biomedical Research Institute of A Coruña (INIBIC), A Coruña, Spain \\ ${ }^{3}$ Medicine DepartmentUniversity of A Coruña, A Coruña, Spain \\ ${ }^{4}$ Oncology Research UnitA Coruña Universtiy Hospital, A Coruña, Spain
}

\begin{abstract}
Intracellular signalling mediated by secreted Wnt proteins is essential for the establishment of cell fates and proper tissue patterning during embryo development and for the regulation of tissue homeostasis and stem cell function in adult tissues. Aberrant activation of Wnt signalling pathways has been directly linked to the genesis of different tumours. Here, the components and molecular mechanisms implicated in the transduction of Wnt signal, along with important results supporting a central role for this signalling pathway in stem cell function regulation and carcinogenesis will be briefly reviewed.
\end{abstract}

\section{Keywords}

Wnt; $\beta$-catenin; APC; Cancer; Cancer stem cells

\section{Introduction}

Wnt proteins, initially identified as the products of the Drosophila Wingless (Wg)and mouse Int1 genes, are secreted cysteine-rich glycosylated proteins playing essential roles during embryo development and in the maintenance of adult tissue homeostasis [1-6] (for a comprehensive overview, the reader is referred to the Wnt gene homepage:

http://www.stanford.edu/ rnusse/wntwindow.html). During embryo development, Wnt signalling has a key role in controlling the pattern of body axis formation as well as in the development and maturation of the cardiovascular and central nervous systems and the limbs [1-6]. At this stage of development, altered Wnt signalling leads to abnormal morphogenesis and congenital defects [16]. Dysfunction of the Wnt pathway can also result in neurodegenerative disorders and heart failure [1-6].

In adult tissues, Wnt signalling is essential for the regulation of the self-renewal, proliferation and differentiation of pluripotent stem cells [1-6]. Wnt signalling is also involved in the regulation of cell proliferation, differentiation and survival in several differentiated somatic cell types and in cancer cells [1-6]. Consistent with these observations, different components of the Wnt signalling pathway have been linked to tumorigenesis, including adenomatous polyposis, colon carcinoma, medulloblastoma, tuberous sclerosis and lung cancer. 


\section{Wnt proteins and Wnt receptors}

Wnt genes have been identified in a large number of organ-isms, from hydra to human, encompassing a wide protein family of paracrine growth factors [1]. Similarly, more than eighty target genes of Wnt signalling have been identified in different species from mammalian human and mouse, to zebrafish, Xenopus and Drosophila[1]. In humans, at least 19 of the 24 potential gene sequences encoding known WNT proteins, as well as their precise chromosome locations, have been accurately identified, many of them located in very close positions in the genome (see Table 1) [1].

Table 1. Chromosomal location of WNT genes in humans

\begin{tabular}{ll}
\hline Gene & Location \\
\hline WNT1 & $12 \mathrm{q} 13$ \\
WNT2 & $7 \mathrm{q} 31$ \\
WNT2b/13 & $1 \mathrm{p} 13$ \\
WNT3 & $17 \mathrm{q} 21$ \\
WNT3a & $1 \mathrm{q} 42.13$ \\
WNT4 & $1 \mathrm{p} 35$ \\
WNT5a & $3 \mathrm{p} 14-\mathrm{p} 21$ \\
WNT5b & $12 \mathrm{p} 13.3$ \\
WNT6 & $2 \mathrm{q} 35$ \\
WNT7a & $3 \mathrm{p} 25$ \\
WNT7b & $22 \mathrm{q} 13.3$ \\
WNT8a/d & $5 \mathrm{q} 31$ \\
WNT8b & $10 \mathrm{q} 24$ \\
WNT10a & $2 \mathrm{q} 35$ \\
WNT10b/12 & $12 \mathrm{q} 13.1$ \\
WNT11 & $11 \mathrm{q} 13.5$ \\
WNT14 & $1 \mathrm{q} 42$ \\
WNT15 & $17 \mathrm{q} 21$ \\
WNT16 & $7 \mathrm{q} 31$ \\
\hline
\end{tabular}

Wnt genes have been identified in vertebrates and in-vertebrates, but not in plants, unicellular eukaryotes such as Saccharomyces cerevisiae or prokaryotes [1]. In vertebrates, Wnt orthologues in different species are highly similar in sequence [1]. For example, human and mouse, Wntlorthologues are 98\% identical, and human and Xenopus wnt5aare $84 \%$ identical at the amino-acid level. Phylogenetic analyses of vertebrate and invertebrate Wnts demonstrate significant orthologous homology between several human and Drosophila Wnt genes [1]. However, the evolutionary relationship between the five Caenorhabditis elegans Wnt genes and human WNT genes is less apparent [1].

Human WNT proteins (Fig. 1) are lipid-modified secreted glycoproteins of very similar size, typically containing 350-400 amino acids, and ranging in molecular weight from $39 \mathrm{kDa}$ (WNT7A) to $46 \mathrm{kDa}$ (WNT10a) [3]. Little is known about the structure of Wnt proteins, as they are notoriously insoluble, but it is well established that all of them have 23 or 24 cysteine residues and several highly conserved asparagine-linked glycosylation sites [7, 8], suggesting that Wnt protein folding may depend on the formation of multiple intramolecular disulphide bonds. Analysis of the signalling activities of chimeric Wnt proteins has shown that the carboxy-terminal region of Wnt proteins may play a role in determining the specificity of responses to different Wnts [9]. 


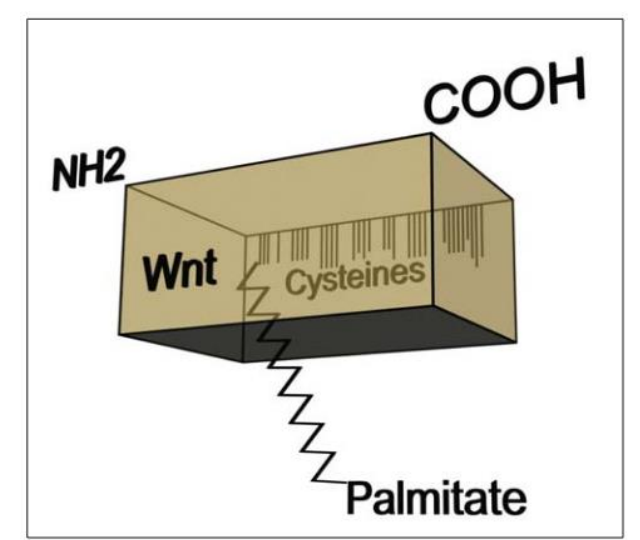

Fig. 1. Schematic representation of the Wnt protein showing the approximate positions of cysteine residues. The palmitoylation of wild type Wnt occurs through a thioesther to a cysteine

As a general rule, Wnt proteins are secreted paracrine factors that can act in a cell nonautonomous manner. Once secreted, Wnt proteins can associate to glycosaminoglycans in the extracellular matrix and tightly bind the cell surface [10,11]. Although tightly bound to the plasma membrane, it has been reported that active Wnt factors are also found in the conditioned medium of cultured cells [11]. Apart from these scant observations, the precise localization of Wnt proteins in vertebrates is poorly understood

Analysis of the localization of $\mathrm{Wg}$ in Drosophila, how-ever, has provided critical insights into the subcellular distribution of Wnt proteins and the importance of this distribution for signalling activity. In the embryonic epidermis, $\mathrm{Wg}$ is localized either in intercellular regions that are associated with the plasma membrane in producing paracrine cells or in multi-vesicular bodies inside Wg-receptor cells, suggesting that $\mathrm{Wg}$ is transmitted and received through the endocytic pathway [12]. This idea is supported by examination of shibire embryos harbouring a mutation in dynamin, a critical component of the endocytic machinery. Dynaminmutants show defects in $\mathrm{Wg}$ distribution and $\mathrm{Wg}$ signalling activity is compromised. Similarly, expression of a dominantnegative form of shibire also reduces $\mathrm{Wg}$ activity $[13,14]$.

Endocytosis may also contribute to limit the distribution of $\mathrm{Wg}$ signal in Drosophila. Thus, in developing tissues, cells positioned in an anterior location respective to the $\mathrm{Wg}$ source showed significantly lower levels of $\mathrm{Wg}$ in endocytic vesicles than cells located posterior to $\mathrm{Wg}$-producing cells. The asymmetric distribution of $\mathrm{Wg}$ closely mimics the activity of the secreted factor, exhibiting the strongest short range signalling effect in the posterior as compared to the anterior direction with respect to $\mathrm{Wg}$-producing cells. Such critical differences in $\mathrm{Wg}$ distribution are the result of a rapid degradation of the endocytosed $\mathrm{Wg}$ in posterior cells regulated by the epidermal growth factor receptor (EGFR) [15].

Association of $\mathrm{Wg}$ with specific membrane microdo-mains also plays a role in controlling the distribution of $\mathrm{Wg}$ signals during Drosophila development. In imaginal discs, $\mathrm{Wg}$ is found in specialised membrane vesicles called argosomes, which are thought to be derived from lipid raft microdomains [16]. Incorporation of $\mathrm{Wg}$ into argosomes requires heparin sulphate proteoglycans, suggesting that proteoglycans play a role in sorting $\mathrm{Wg}$ to specialised membrane microdomains in Wg-producing cells or, alter-natively, may play a role localising $\mathrm{Wg}$ in distinct endocytic compartments in receiving cells. 
Polarised distribution of $\mathrm{Wg}$ transcripts in embryonic epithelial cells is also required for optimal signalling activity. High-resolution in situ hybridisation analyses demonstrate that $\mathrm{Wg}$ transcripts are localised apically in the embryonic epidermis and that this distribution is mediated by two cis-acting elements found in the $3^{\prime}$ UTR of the Wg mRNA [17]. Mutation of these elements results in uniform localisation of $\mathrm{Wg}$ transcripts and impaired $\mathrm{Wg}$ protein distribution and signalling. The asymmetric distribution of $\mathrm{Wg}$ transcripts is dependent on dynein-mediated microtubule transport [18].

Wnt proteins are usually divided into functional classes based on their ability to stimulate secondary body axis formation in Xenopus embryos and to activate specific signalling cascades through the Dishevelled (DVL) factor, a multifunctional phosphoprotein acts as a central transducer of the Wnt signal at the plasma membrane as well as in the cytoplasm or cell nucleus $[19,20,21]$. Different Wnt proteins use different molecular pathways to activate specific gene transcription

The canonical Wnt pathway (see below) use $\beta$-catenin (Ctnnb1) as the central component and involves Wnt1, Wn-t3a and Wnt8. Members of the Wnt 1 class are stimulators of a secondary body axis in Xenopusand include Wnt1, Wnt2, Wnt3, Wnt3a, Wnt8 and Wnt8a. Wnt proteins of this class bind to the Fzd transmembrane receptor and to the lipoprotein-related protein 5/6 (Lrp5/6) co-receptor.

There are two other known pathways used by Wnt proteins to activate gene transcription (see below). The non-canonical $\mathrm{Wnt} / \mathrm{Ca}^{2+}$ pathway uses intracellular calcium $\left(\mathrm{Ca}^{2+}\right)$ release as a central component and involves Wnt4, Wnt5a and Wnt11 [22]. The Wnt5a class cannot induce secondary axis formation in Xenopus and includes the Wnt proteins of Wnt4, Wnt5a, Wnt5b, Wnt6, Wnt7a and Wnt11. In the planar cell polarity (PCP) pathway, Wnt proteins bind the Fzd transmembrane receptor and use Dvl to activate effector pathways through Rho and Rac small GTPases and Jun $\mathrm{N}$-terminal kinase (Jnk) [23]. In the Wnt- $\mathrm{Ca}^{2+}$-dependent pathways, calcium-dependent kinases are activated through G-protein signalling that leads to a rise in intracellular $\mathrm{Ca}^{2+}$ either through cGMP or phospholipase activation [24, 25].

In mammals, receptors of Wnt proteins encompass at least ten isoforms of the Fzd protein family. The Fzd proteins are named after the fi rst member of the Drosophila tissue polarity gene Frizzled (Fzd). Members of the Fzd protein family are considered as a distinct family of G-proteincoupled receptors [26]. Interestingly, Fzd proteins can bind proteins from other protein families, such as Spondin and Norrin, and the Fzd CRD also exists in several other proteins that include the soluble secreted Fzd-related proteins (Sfrp) [27], some receptors of tyrosine kinases [28], carboxypeptidase $Z$ [29] and an isoform of collagen [30]. These proteins can act as important regulators of Wnt-Fzd signalling.

In addition to the Fzd protein receptors, other obligate co-receptors also are necessary for canonical Wnt signalling. The best known are the low-density-lipoprotein receptor 5/6 family (Lrp5/6) [31]. In the canonical Wnt-Fzd pathway, Wnt binds to both the Fzd receptor and Lrp5/6 [31], resulting in the inhibition of the downstream component glycogen synthase kinase$3 \beta(G s k 3 \beta)$. Wnt signalling can also be transmitted through the binding of extracellular domain of Lrp5/6 to Axin, a key component in the Gsk3ßcomplex, indicating that the Lrp5/6 receptor is an important part of the Wnt-Fzd signalling pathway [32, 33].

Ryk represents another co-receptor of Wnt signalling belonging to one of the divergent members of the receptor tyrosine kinase family. Ryk can form a complex with Fzd proteins inducing the activation of the canonical Wnt signalling pathway, and regulate the non-canonical Wnt signalling through Fzd-independent pathways [34, 35]. 


\section{Wnt protein secretion, extracellular transportand reception}

Different proteins involved in Wnt protein processing and secretion from producing paracrine cells have been identified, including the porcupine acyl-transferase, the multi-pass transmembrane protein wntless/eviand the Retromer complex [2] (Fig. 2). These proteins are involved in the palmitoylation of Wnt proteins in the endoplasmatic reticulim (porcupine) and in the transport of palmytoilated Wnt proteins to secretory vesicles, formation of lipid particles and subsequent secretion (wntless/eviand the Retromer complex). Genetic screens have identified the multipass transmembrane protein wntless (wls)/evenness interrupted (evi) as a key component of the Wnt secretory pathway [36]. In Drosophila and mammalian tissue culture, RNAi knock-down of wls/evi/mom-3 in cells overexpressing Wnt inhibits a Wnt-responsive luciferase reporter in cocultured responding cells, showing that wls/evi acts in a cell non-autonomous manner [37]. Wls/evi deficiency inhibits Wnt transport to the surface of cells [38]. These phenotypes are similar to those observed in porcupine mutants. In contrast to the function of Porcupine, however, the secretory activity mediated by wls/evi does not depend on the palmitoylation status of Wnt proteins: the secretion of Wnt proteins in which the palmitoylation site is mutated is still impaired in wls/evimutants.

Recently, large molecules required for lipid transport called lipoprotein particles have been implicated in the transport of Wnt proteins and other lipid-modified proteins such as Hedgehogs [2] (Fig. 2). While previously postulated to be exosome-like particles, these structures, termed argosomes, are now thought to be exogenously derived lipoproteins. A model is proposed where palmitoylated proteins associate with lipoprotein particles on the extracellular face of cells. Traffic of Wnt proteins from one cell to the next requires this association, as RNAi knock-down of lipophorin, a Drosophilalipo protein, narrows the range of Wg signalling in the wing disc. It will be interesting to see what mechanism underlies these lipoprotein particles' aiding in Wnt transport and whether this mechanism of Wnt transport is conserved across all species. In addition, transcytosis may regulate Wnt movement. In yeast, proteins of the retromer complex direct endosomal-Golgi retrieval of proteins. In vertebrate systems, the retromer complex func-tions in basal-to-apical transcytosis [39]. In C. elegans, the orthologue of the yeast retromer complex subunit Vps35p is required for the long-range signalling capabilities of Egl20 (C. elegansWnt orthologue) [40]. It has been pro-posed that the retromer complex promotes the association of secreted Wnts with other proteins required for ligand transport, such as lipoprotein particles (Fig. 2).

The seven-pass transmembrane Fzd protein was the first receptor found to transduce a Wnt signal (Fig. 3). Fzd proteins contain a large extracellular domain containing a conserved motif comprised of 10 cysteine residues called the cysteine-rich domain (CRD). The CRD domains from different Fzd receptors can bind to multiple Wnt proteins with high affinity [41]. At the cytoplasmic side, Fzd receptors may directly interact with the Dishevelled (DVL1) protein, a central transducer of Wnt signalling (Fig. 3).

The single-pass transmembrane proteins of the low-density lipoprotein (LDL) family called Lrp5 and Lrp6 are require to translate Wnt signalling into the cytoplasm of receptor cells [31]. Following Wnt binding, Fzds forms a complex with co-receptor LRP proteins that can activate intracellular targets. LRP5 and LRP6 proteins have a relatively small intracellular domain and a large extracellular domain containing several potential protein interaction domains [42]. Altered proteins that lack the extracellular portion but still contain the transmembrane and intracellular domains produce a constitutively active canonical Wnt signal.

Interestingly, the Axin protein, a negative regulator of Wnt signalling, can bind to the cytoplasmic tail of Lrp6, providing a mechanism by which Axin is released from $\beta$-catenin [32]. This interaction changes the fate of $\beta$-catenin; instead of being destroyed, it is accumulated in the cytoplasm inducing Wnt-dependent gene transcription. The binding of Axin to the Lrp6 tail is promoted by phos-phorylation of Lrp6 with a central PPPSP motif as a hall-mark. The serine in the PPPSP motif is modified by Gsk3b, leading to activation of signalling [43]. 


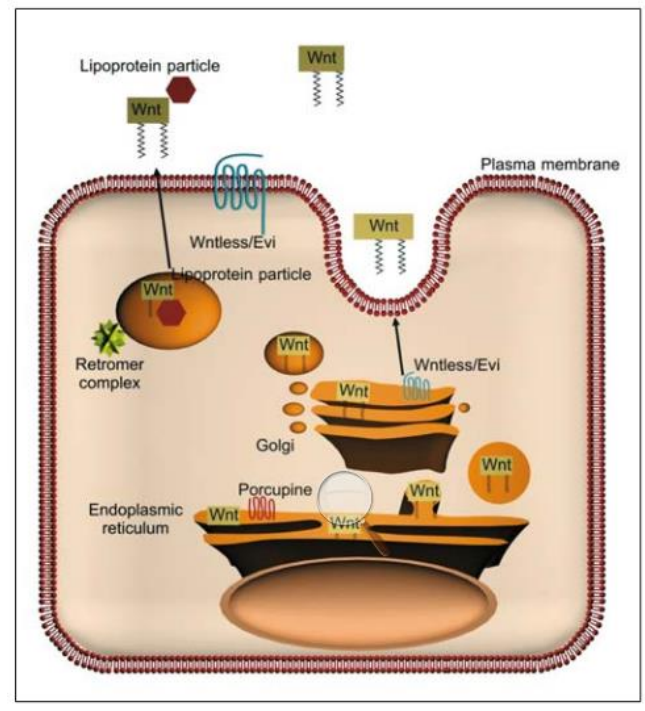

Fig. 2. In Wnt-producing cells, the Wnt protein is palmitoylated in the endoplasmic reticulum by the porcupine acyl-transferase. Further transport and secretion of the Wnt protein in secretory vesicles is con-trolled by the multi-pass transmembrane protein Wntless/Evi, which is present in the Golgi and/or on the plasma membrane. The retromer complex may act in the cytoplasm of Wntproducing cells to generate Wnt forms that can be transported outside the cells in the form of a lipoprotein particle

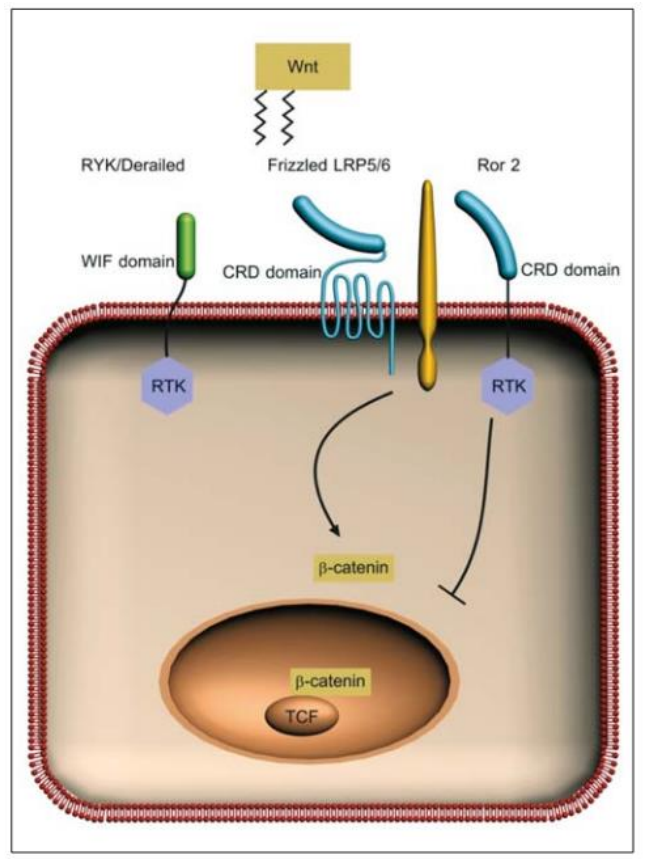

Fig. 3. Wnt proteins can interact with multiple receptors. In the canonical Wnt/ $\beta$-catenin signalling pathway, Wnt proteins interact with Frizzled receptors through the CRD domain. The LRP5/6class of transmembrane lipoproteins act as co-receptors of Frizzled. The RYK/Derailed-type receptors have a tyrosine kinase motif and a WIF ligandbinding domain that can bind Wnt proteins in Frizzelddependent or -independent mechanism. Finally, Wnt scan also interact with the Ror tyrosine kinases to mediate a signal that can inhibit $\beta$-catenin TCF activity in the nucleus

There are other proteins with known Wnt-binding do-mains that can serve as receptors for Wnt ligands. The single-pass tyrosine kinase Ror2, although structurally distinct from Fzds receptors, is involved in Wnt signalling [44, 45]. Ror2 can mediate the Wnt5a signal that is responsible for inhibition of $\beta$-catenin-TCF signalling [46]. Thus, the CRD domain may enable alternative signalling pathways in response to Wnt ligand stimulation. Another well characterised Wntbinding domain is the Wnt inhibitory factor (Wif) module, which is also found in the cell surface atypical receptor tyrosine kinase RykK. In mammalian systems, Ryk is required for Wnt3amediated canonical Wnt signal-ling [35]. Understanding the ways in which alternative Wnt receptors such as Ryk and Ror2 interact with known Wnt signalling components and what intracellular signalling cascades they initiate will lead to stimulating advances in this issue.

\section{Wnt signalling and embryo development}

Wnt proteins are essential for embryogenesis, as demonstrated by the loss-of-function experiments in mice models of 9 of the 18 mouse Wnt genes (see Table 2). A full list of Wnt genes and their mutant phenotypes in vertebrates and invertebrates can be found at the Wnt gene homepage (http://www.stanford.edu/ rnusse/wntwindow.html). 
Table 2. Developmental functions of mouse Wnt genes

\begin{tabular}{|c|c|c|}
\hline Gene & Natural allele & Phenotype of knockout functions \\
\hline Wnt1 & Swaying & $\begin{array}{l}\text { Loss of a portion of midbrain and cerebellum; deficiency in dorsal neural-tube derivatives, } \\
\text { including neural-crest cells in double knockout with Wnt3a }\end{array}$ \\
\hline Wnt2 & & Placental defects \\
\hline Wnt3 & & Defects in axis formation and gastrulation; defects in hair growth and structure \\
\hline Wnt3a & Vestigial tail & $\begin{array}{l}\text { Defects in somite and tailbud development; deficiency in dorsal neural-tube derivatives, } \\
\text { including neural-crest cells in double knockout with Wnt } 1 \text {; loss of hippocampus }\end{array}$ \\
\hline Wnt4 & & $\begin{array}{l}\text { Defects in kidney development; defects in female development; absence of Müllerian duct, } \\
\text { ectopic synthesis of testosterone in females; defects in mammary gland morphogenesis }\end{array}$ \\
\hline Wnt5a & & Truncated limbs, shortened anterior-posterior axis, reduced number of proliferating cells \\
\hline Wnt7a & $\begin{array}{l}\text { Postaxial } \\
\text { hemimelia }\end{array}$ & $\begin{array}{l}\text { Defects in limb polarity; female infertility due to failure of Müllerian duct regression; defects } \\
\text { in uterine patterning; defects in synapse maturation in the cerebellum }\end{array}$ \\
\hline Wnt7b & & Placental defects \\
\hline Wnt10b & & Inhibition of adipogenesis \\
\hline
\end{tabular}

Overexpression and antisense knockdown analyses in Xenopus have demonstrated that the $\mathrm{Wnt} / \beta$-catenin path-way is required for the specification of dorsal cell fates [47]. XenopusFzd7 is important for establishing dorsal cell fates, suggesting that Wnt ligand in also important in this process [48]. Targeted knockout of Wnt3in mice results in defects in axis formation and gastrulation, suggesting a conserved role for Wnts in controlling the establishment of the dorsalventral axis in vertebrates.

In flies, Wnt signalling has several functions during development. The wg gene is necessary for cell fate choices in the ventral epidermis during embryogenesis, as well as for many other functions, and Drosophila Wnt2 is required for testis and adult muscle development. In C. elegans, genetics studies have defined a number of roles of Wnts, including establishment of polarity and endodermal cell fates in the early embryo and regulation of cell migration, as an example.

In the mouse intestine, Wnt signalling is the central cell fate determinant along the crypt-villus axis [49]. The stem cell niche in the crypt of the intestine is destroyed in neonatal mice lacking the transcription factor Tcf4 [50]. In these mice, the differentiated villus epithelium is normal, indicating that Wnt signalling is required for the establishment of the intestine niche but not for cell differentiation. Transgenic mice over-expressing the Wnt agonist R-spon-din-1 present hyperproliferation of intestinal crypts [51], indicating that Wnt is an essential mitogen for crypt stem cells.

Wnt signalling is also required for hair follicle development. Mice lacking Lef1present a significantly reduced number of hair follicles [52], while transgenic Lef1over-expression promotes de novo hair follicle formation [53]. In the same way, transgenic over-expression of a metabolically stable form of $\beta$-catenin induces the formation of hair follicles [53]. By contrast, conditional deletion of $\beta$-catenin or transgenic over-expression of a dominant negative form of Lef1 aborts the development of hair follicle precursors [54]. These observations implicate that Wnt signalling through Leflis essential to activate the differentiation programme of the hair follicle precursor resident in the bulge region of the hair follicle [55]. In the haematopoietic system, overexpression of $\beta$-catenin or stimulation with purified Wnt proteins promotes the proliferation and self-renewal of haematopoietic stem cells in vitro[56]. 


\section{The Wnt signalling pathways}

\section{The canonical Wnt pathway}

The canonical Wnt signalling pathway is referred to as the Wnt/ $\beta$-catenin pathway since it can regulate $\beta$-catenin protein levels to control the activation of Wnt-responsive target genes (Figs. 4 and 5). All Wnt signalling pathways are initiated by interaction of Wnt proteins with Fzd receptors, but in this pathway the Wnt signalling pathway will only be activated if the binding of the Wnt protein to the Fzd receptor takes place in the presence of the co-receptor Lrp5/6 resulting in the formation of a Wnt:Fzd:Lrp5/6 tri-molecular complex [31, 32]. Once Wnt protein binds to the Fzd receptor and the co-receptor Lrp5/6, this is followed by recruitment of Dvl [57]. The formation of the Wnt-Fzd-Lrp5/6 complex also promotes the Lrp5/6-mediated degradation of Axin [32]. The inhibition of Gsk3b activity by Wnt with the degradation of Axin blocks the formation of the protein complex consisting of Gsk3b, Axin, and adenomatous polyposis coli (Apc) tumour suppressor protein. If the formation of the protein complex of Gsk3b, Axin and Apc tumour suppressor protein does not occur, accumulation of free $\beta$-catenin results in its translocation to the nucleus.

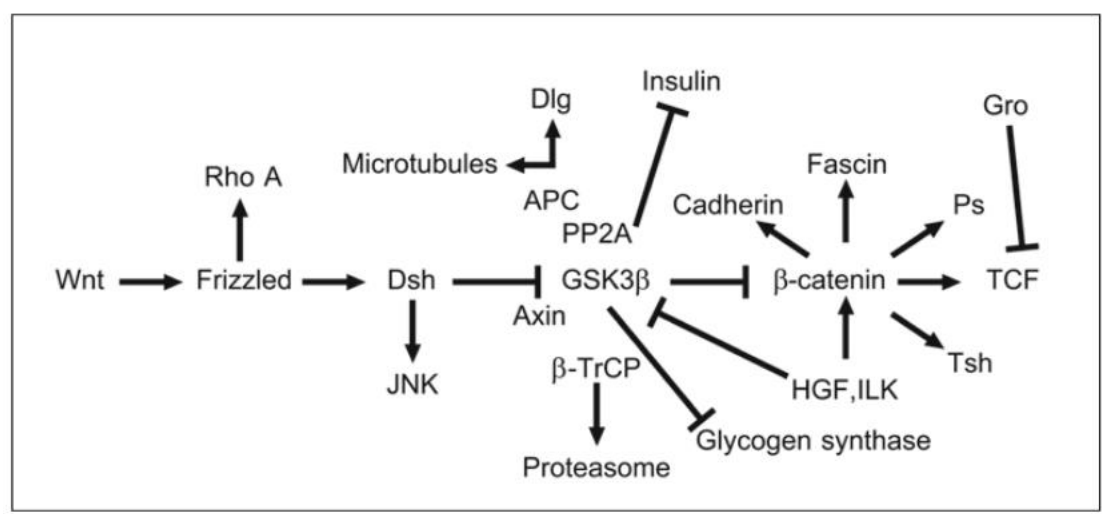

Fig. 4. Schematic representation of the canonical Wnt/ $\beta$-catenin signalling pathway showing the links other processes and pathways through different interactions of individual components

Once positioned in the nucleus, the free $\beta$-catenin acts as a transcription factor and activates Tcf and Lef by forming nuclear complexes with members of the Tcf/Lef transcription factor family [58]. This leads to the transcription and expression of a variety of Wnt-responsive target genes such as Myc, Ccnd1(cyclin D1) and Axin2. In addition, the complexes of Tcf/Lef and $\beta$ catenin may cooperate with factors activated by other signalling pathways to alter cellular remodelling processes. The canonical Wnt signalling pathway is also activated by several other cellular mechanisms. The shifting of proteins from the cadherin-bound pool to the cytoplasmic pool can increase the amount of available free $\beta$-catenin for the activation of target genes. Several receptor tyrosine kinases can phosphorylate tyrosine residues of the $\beta$-catenin and cadherincatenin complex to allow $\beta$-catenin to become dissociated from the complex and enhance the amount of $\beta$-catenin in the cyto-plasm for subsequent translocation to the nucleus.

Furthermore, surface receptors, such as EGFR, Mst1r (c-Ron), Erbb2 and erythropoietin receptor (Epor) can then stimulate the canonical Wnt signalling pathway [59,60]. In addition, both insulin-like growth factor and erythropoietin (EPO) lead to $\beta$-catenin stabilisation [60]. The canonical Wnt signalling pathway can also regulate cyclin D1 activ-ity through inhibition of GSK3 $\beta$, Creb (cAMP-responsive-element-binding protein) and PKA (protein kinase A) signalling $[61,62]$. 


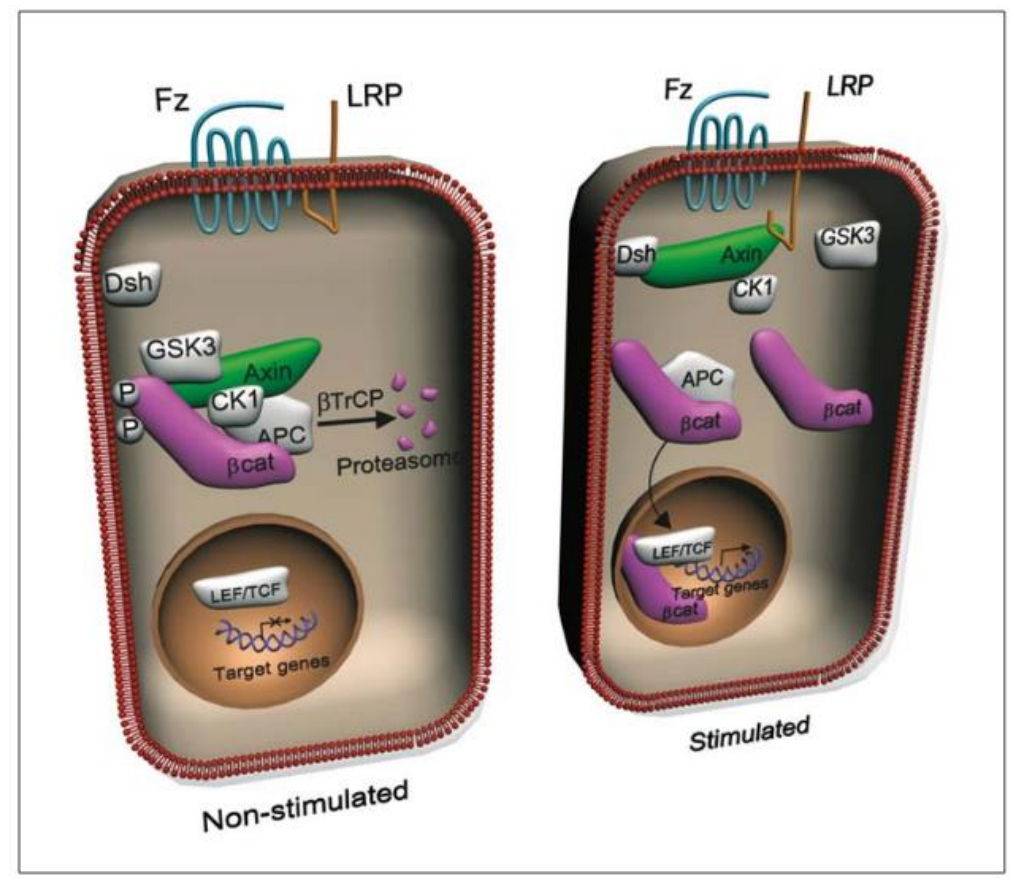

Fig. 5. Canonical Wnt signalling pathway. In the absence of secreted Wnt proteins, $\beta$ catenin is rapidly phosphorylated by a complex containing Axin, APC and the GSK3 and CKI protein kinases. Phosphorylated $\beta$-catenin is recognised by the Slimb/ $\beta$-TrCP component of the E3 ubiquitin ligase, ubiquitinated, and targeted for destruction by the proteasome. In the presence of the Wnt signal, the destruction complex is disorganised by recruitment of Axin to the cell membrane by Dsh. Metabolically stable $\beta$-catenin can accumulate in the cytoplasm and translocate to the nucleus to interact with members of the Lef/Tcf family of transcription factors and activate gene transcription

\section{The Wnt/calcium pathway}

Wnt-induced release of intracellular calcium is sufficient to activate different intracellular calcium-sensitive enzymes such as protein kinase C, Prkc [63, 64], calcium-calmodu-lindependent kinase II, Camk2 [65, 66] and the calcium-sensitive phosphatase calcineurin (Ppp3C) that subsequently can activate the transcription factor Nfat (Fig. 6) [67]. Calcium signalling is a rapid event upon receptor stimulation.

Purified Wnt5a or Wnt5a-derived peptides are able to trigger calcium release in several cell types [24, 66, 68]. The release of intracellular calcium is a rapid response of a cell within seconds upon ligand binding and depends on heterotrimeric G-proteins [24] and the activation of the phosphatidyl inositol cycle. Through the regulation of Pde6, a cGMP-specific phosphodiesterase, this pathway is also linked to the regulation of protein kinase $G$ in some cell types [24]. The $\mathrm{Wnt} /$ calcium pathway has been linked to the activation of nemo-like kinase (Nlk), which is able to phosphorylate Tcf transcription factors and consequently inhibits canonical Wnt signalling. This pathway is involved in dorsoventral patterning of early Xenopusand zebrafish embryos [69], regulation of the $\mathrm{Wnt} / \beta$-catenin pathway [70], tumour formation [66] and more recently the regulation of epithelial-mesenchymal transitions [71]. 


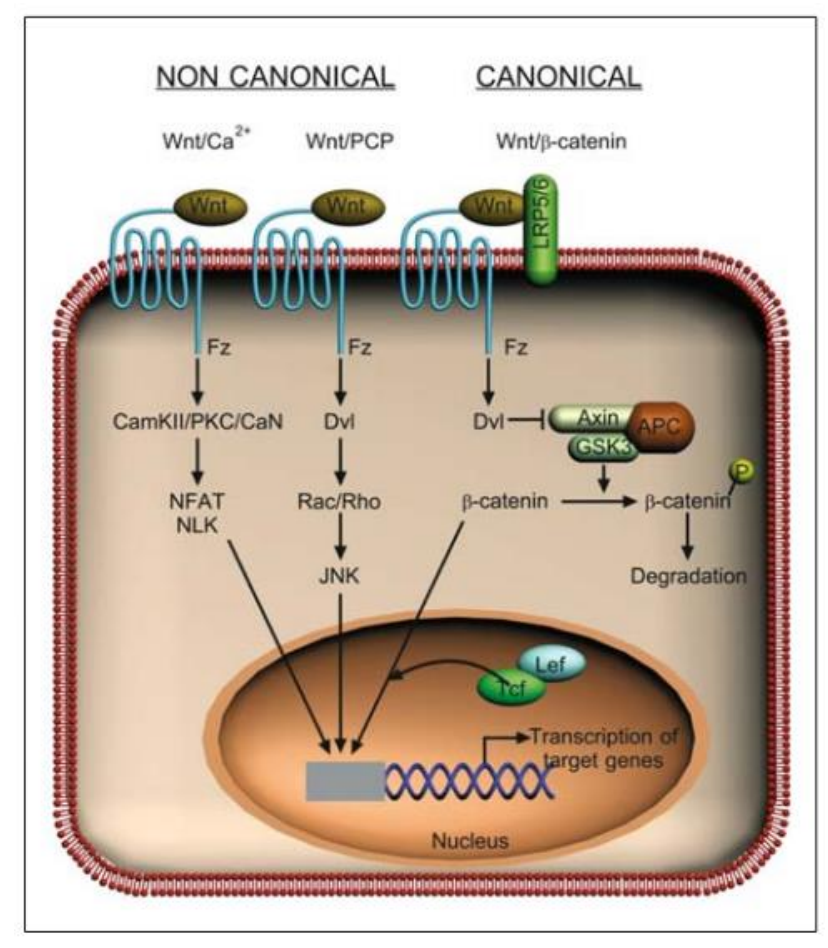

Fig. 6. Canonical versus non-canonical Wnt signalling pathways. Binding of different Wnt proteins to different receptor complexes can result in the specific activation of either the canonical Wnt pathway or a non-canonical Wnt pathway (the $\mathrm{Ca}^{2+}$-dependent or the PCP pathway) resulting in the selective activation of a specific set of target genes

\section{The Wnt/JNK or PCP pathway}

This pathway forms the third signalling pathway activated by Wnts. This pathway was described earlier in D. melano-gaster as the PCP pathway. This pathway regulates the polarity of epithelial cells within the plane of the epithelium. In vertebrates, a similar pathway has been described regulating convergent extension movements during gastrulation or neurulation and cell migration of neural crest cells [72, 73]. On the other hand a distinct Wnt (Wingless) ligand has not been assigned to this pathway in Drosophila; in vertebrates Wnt11 or Wnt5a is able to activate this signalling cascade. The core element of the Wnt/JNK pathway (Fig. 6) includes the activation of Rho GTPases and related proteins such as RhoA, Akt1 (Rac) or Cdc42 downstream of Dvl111 (DSH). The GTPases can activate more down-stream mediators like Jnk or Rho kinase.

In PCP signalling, this cascade of events is complemented by transmembrane proteins such as strabismus (Stbm, official name Vang), diego (dgo) or prickle (pk) that also can bind dishevelled $[74,75]$. It is thought that the asymmetric distribution of proteins such as stbm and pk within epithelial cells is involved in setting up planar polar-ity [75]. In vertebrates, the receptor tyrosine kinase ROR2 has been shown to regulate convergent extension movements and bind to Wnt protein [76]. Ror2 was found to be upstream of Cdc42 and to regulate JNK activity [45]. 


\section{G-proteins in Wnt signaling}

Recent findings indicate the involvement of G-proteins in canonical signalling as well as PCPtype signalling. Activation of Fzd1 signalling through inducible Fzd receptors in F9 theratocarcinoma cells required the function of $\mathrm{G} \alpha_{\mathrm{q}}$ and $\mathrm{G} \alpha_{0}$, whereas triggering Fzd2 signalling through the corresponding inducible Fzd receptor requires $G \alpha_{o}$ and $G \alpha_{t}$. Further evidence was provided by the observation that overexpression of Rgs4, a regulator of G-protein signalling, in early Xenopusembryos interferes with Wnt8-induced secondary axis formation [77]. Tcf/ $\beta$ catenin-mediated reporter gene activity as well as endogenous Wnt/ $\beta$-catenin target genes can be induced by constitutively active $\mathrm{G} \alpha_{o}$ and $\mathrm{G} \alpha \mathrm{q}$ subunits [78]. Depletion of G-proteins by the use of antisense oligonucleotides or siRNA interferes with Wnt- and Fzd-induced activation of the Wnt/ $\beta$-catenin pathway [78]. In Drosophila, genetic epistasis experiments are indicative of the involvement of G-proteins downstream of Fzd but upstream of Dvl in both canonical and noncanonical Wnt signalling [79].

The list of G-protein subunits involved in Wnt signal-ling becomes even longer if one considers the finding that some Wnts probably activate protein kinase A through the classical $G \alpha_{\text {s }}$ pathway [61] whereas a non-canonical Wnt ligand-like Wnt11 reduces Prka activity through $G \alpha_{i}$ [80]. PRKA has been correlated to the regulation of $\beta$-catenin stability as well as JNK activity [80]. Taking into account the fact that the Wnt/calcium pathway also involves G-proteins as outlined above, it seems very probable that all three Wnt signalling branches involve heterotrimeric G-proteins. Considering Wnt signalling to be G-protein coupled indeed leaves us with a plethora of different Wnt/Fzd/G-protein and co-receptor combinations for potential downstream effects.

\section{Secreted antagonists of the Wnt signalling pathway}

Secreted frizzled related proteins (Sfrp) are multifunctional modulators of Wnt and bone morphogenetic protein (Bmp) signalling that are required for the development of most organs and the homeostasis of different adult tissues [2]. Sfrp fold in two independent domains: the cysteinerich domain (Sfrp-CRD) related to the extracellular portion of Fzd and the Netrin module (SfrpNTR) defined by homologies with molecules such as Netrin 1, inhibitors of metalloproteases and complement proteins. Due to its structural relationship with Fzd, it is believed that Sfrp-CRD interferes with Wnt signalling by binding and sequestering the ligand. In contrast, the functional relevance of the SFRP-NTR has been barely addressed [2].

The Sfrp-CRD contains ten cysteines with a pattern of five disulphide bridges identical to that of the extracellular CRD of Fzd [81, 82]. Due to this structural relationship, it is generally assumed that SFRP-mediated Wnt signalling inhibition results from the interaction between the ligand and Sfrp-CRD, which has been actually shown to immuno-precipitate with Wnt1 and Wnt2 [83, 84]. However, Sfrp-CRD can also form homo- and heterodimers with the CRD domain of Fzd receptors [83], suggesting potential alternative mechanisms of action.

Sfrp of different subgroups have different biochemical interactions with Wnt ligands. In support of this assumption, plasmon resonance binding studies using Sfrp1, 2, 3, 4 and Wnt3a and Wnt5 have shown that Wnt5 binds preferentially to Sfrp1 and 2, while Wnt3a binds at least two sites in Sfrp1, 2, 4 and one in Sfrp3 [85]. Sfrp molecules interact with both Wnt and Fzd in multiple ways and these interactions can modulate signal transduction in either a positive or negative manner. There are several possible mechanisms by which Sfrp can modulate Wnt signalling (Fig. 7). SFRP could sequester Wnt ligands through the NTR domain, thus acting as antagonists (Fig. 7a) or act in a dominant-negative manner through the formation of inactive complexes with Fzd receptors, preventing signal activation (Fig. 7b). Alter-natively, SfrpP could favour Wnt-Fzd interaction by simultaneously binding to both molecules and, thus, synergising with signal activation (Fig. 7c). Finally, in the absence of Wnt ligands, Sfrp-CRD: Fzd-CRD heterodimer formation could trigger signal transduction (Fig. 7d). Notably, the activation of the Fzd receptors by a proposed ligand-antagonist is not unique to Sfrp1, as Dkk2, which belongs to a 
different family of Wnt antagonists, can activate Wnt canonical signalling cooperating with at least three different Fzd [86].

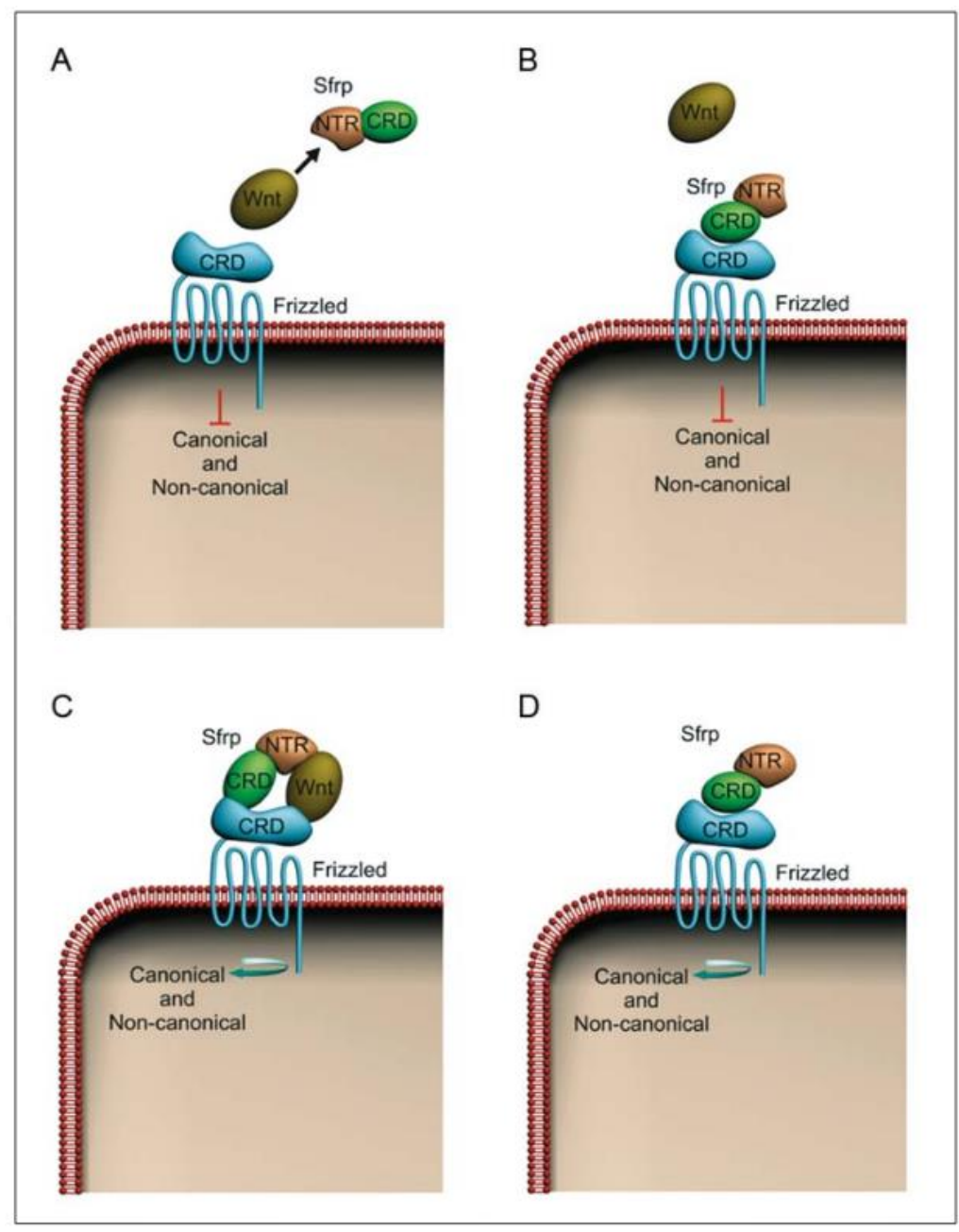

Fig. 7. SFRP mode of action may rely on multiple interactions with Wnt ligands and/or Frizzled receptors. Possible mechanisms by which SFRPs could modulate Wnt/Frizzled signalling: (a) SFRP scan antagonise Wnt activity by directly binding to the ligand through its Netrin-related domain. (b) SFRPs could interact directly with Frizzled receptors through their corresponding CRD motifs and prevent signal transduction. (c) Frizzled, Wnt and SFRP molecules could form heterotrimeric complexes, where SFRP could present the Wnt ligand to the Frizzled receptor thanks to the differential interactions of the CRD and NTR domains. (d) In the absence of Wnt ligands, SFRPs can directly bind a Frizzled receptor and transduce a signal

Genetic manipulations selectively eliminating one or the other domain of Sfrp may provide further insights. Additional studies characterising the functionally relevant interactions among Sfrp-NTR:Wnt or Sfrp-CRD:Fzd pairs are also undoubtedly needed. Interaction with additional components of the Wnt signalling cascade also needs to be addressed. Particularly relevant might be the contributions of proteoglycans, which are known to bind Wnts [87] and may additionally interact with the Sfrp-Ntr. 
Alternative extracellular mechanisms to inhibit Wnt signalling involve Dkk proteins that are secreted regulators which can bind to the co-receptor Lrp5/6 preventing the formation of the Lrp:Fzd:Wnt complex and thus inhibiting the induction of Wnt signalling. Furthermore, in the presence of Kremen1 and 2, two-transmembrane proteins Dkk and Lrp5/6 can form a tertiary complex and to be internalised, reducing the availability of Lrp5/6 receptor for its ligands.

Recently, the two members of a gene family (Sost, encoding sclerostin, and Wise) have been added to this list of extracellular Wnt antagonists. They are capable of binding to Lrp5/6 and, in this way, modulating Wnt signaling.

In the cytosol as well as in the nucleus additional mechanisms are available for regulating the canonical Wnt signalling pathway. The former involves regulation at the level of any of the components of the tertiary Gsk3b:Axin:Apc complex that leads to phosphorylation and subsequently degradation of $\beta$-catenin. Finally the nuclear availability of transcription factors Tcf, Lef and cofactors can influence the signalling.

\section{Wnt signalling and tissue homeostasis}

\section{Wnt signalling in the epithelium}

The Wnt cascade is essential in establishing cell fate along the crypt-villus axis of the intestinal epithelium. $\beta$-Catenin is the major cytoplasmic signal transducer of the canonical Wnt pathway. Accumulation of nuclear $\beta$-catenin, the hall-mark of active Wnt signalling, is evident in the crypt cells of the normal intestine, whereas differentiated villus cells present $\beta$-catenin at their basolateral membrane, where it is important to ensure cell adhesion. Deletion of the transcription factor Tcf4, the most prominent effector of Wnt signalling in the gastrointestinal tract, produces a severe intestinal phenotype accompanied by neonatal lethality.

While the villous epithelial compartment is practically unaffected in these mice, intestinal crypts are completely absent and no proliferating cells are observed, indicating that Wnt signals are required for the maintenance of the crypt proliferative compartment (Fig. 8). In agreement with these fi ndings, inhibition of the Wnt receptor by expression of the secreted antagonist Dkk1 in adult mice leads to a complete loss of crypts. Thus, in physiological conditions, the $\beta$-catenin:Tcf 4 complex drives the transcription of a set of target genes that determine the characteristics of the intestinal crypt cells. Wnt signals are turned off in differentiated cells present in the villi, hence establishing the crypt-villus boundary. The only terminally differentiated cells in the intestine that present nuclear $\beta$-catenin and active Wnt signalling are the Paneth cells (Fig. 8) and this specific fea-ture might account for their downward migration towards the bottom of the crypts, contrary to all the other differenti-ated cell types of the gut.

The same genetic programme that is physiologically active in crypt progenitor cells can also promote colon carcinogenesis. Indeed, loss of the tumour suppressor APC (adenomatous polyposis coli), a key negative regulator of Wnt signals that functions by controlling $\beta$-catenin degradation, is the signature of the vast majority of human intestinal tumours [88], both in hereditary syndromes and in sporadic colorectal cancers. In the rare cases where APC is not inactivated, human intestinal tumours usually show activating mutations in $\beta$-catenin itself, or loss-of-function mutations in Axin2, a protein that cooperates with APC in $\beta$-catenin degradation. These data underscore the central role of Wnt signalling activation in the transformation of intestinal epithelial cells. 


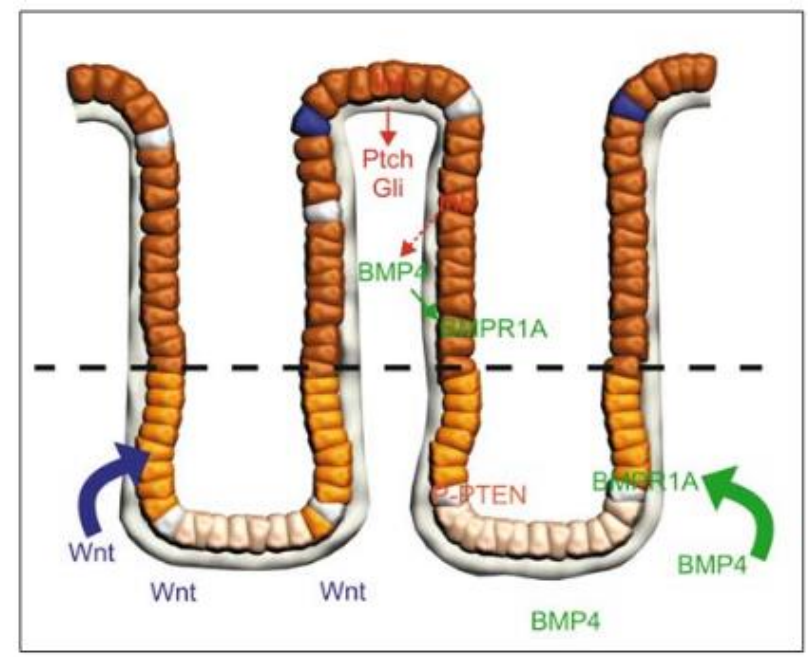

Fig. 8. Wnt and Hh signalling are directly implicated in small intestine homeostasis. Crypt mesenchymal cells express and secrete Wnt ligands that can act as proliferative signals to stimulate the growth and differentiation of crypt cells. Similarly, IHh, expressed and secreted by epithelial cells of the villus, regulates the activity of the underlying stromal cells expressing the Hh effectors Patched (Ptch) and Gli; Ihh also contributes to BMP activation in the mesenchyme

\section{Wht signalling in bone formation}

Osteogenesis is stimulated by canonical Wnt signalling in different ways. In early stages the differentiation of mesenchymal stem cells to osteoblast precursors is stimulated while alternative differentiation of these stem cells towards adipocytes or chondrocytes is inhibited [89]. These early steps can be followed in an ex vivo culture system, referred to as micromass cultures, using mesenchymal limb bud cells from either chicken or mouse embryos. Using this system it has been demonstrated in chickens that a number of Wnt molecules, Wnt1, Wnt3a, Wnt4, Wnt7a, Wnt9a (formerly known as Wnt14) and Wnt11, can inhibit chondrogenesis [90]. The underlying mechanisms resulting in an inhibition of chondrogenesis might be different for the individual ligand; for Wnt9a it was demonstrated that $\beta$-catenin is required for its inhibitory effect [91]. The Wnt ligands, Wnt9A and Wnt7B, are the likely candidates for regulating osteoblastogenesis, since they are expressed in the perichondrium/periosteum and are regulated by Indian Hedgehog (Ihh) signalling [92].

There also exist evidence for an effect of non-canonical Wnt signalling at different stages of bone cell metabolism. Non-canonical Wnt signalling was shown to suppress Pparg function through Camk2-Map3k7 (Tak1)-Map3k7ip2 (Tab2)-Nlk and induce Runx2 expression. This promotes osteoblastogenesis in bone marrow mesenchymal progeni-tors in preference to adipogenesis. Osteoblastogenesis is also stimulated by non-canonical Wnt signalling through Gprotein-linked activation of Prkcd providing another osteogenic mechanism. Finally, an antiapoptotic effect both on osteoblast progenitors and osteoblasts was shown for Src/Mapk1 (Erk) and Pik3 (Pi3k)/Akt signalling, acting synergistically with canonical Wnt signalling. 
The Wnt signalling pathway plays an important role in embryonic development, cell differentiation and cell proliferation [93]. The biological effects of the Wnt pathway are mediated via the regulation of direct (primary) and indirect (secondary) target genes (for a list of target genes see http://www.stanford.edu/ rnusse/pathways/targets.html) [94, 95].

The transcription activation by Tcf/Lef and $\beta$-catenin is a crucial step in the direct target gene activation by the pathway. Thus the activation of a Wnt target gene by Tcf via a Tcf/Lef binding motif within the promoter region indicates the direct regulation. Direct Wnt target genes are the cell cycle kinase activator cyclin D1 and the transcription factors Myc and Etv4 (PEA3) [96]. While the regulatory mechanism of direct target genes is well established, there are few data available about the regulation of indirect Wnt targets. A prominent indirect negative target is the cell cycle kinase inhibitor Cdkn1a (p21/Waf1), which is induced in cells expressing dominant negative Tcf [97]. There are indications that $\mathrm{p} 21 / \mathrm{Waf} 1$ expression is regulated by the relative levels of the Myc interacting zinc finger pro-tein-1 PIAS2 (Miz1) and the direct Wnt target Myc [98].In the absence of Myc, Miz1 activates p21/Waf1 expression, while in the presence of high Myc levels, Miz1 together with Myc functions as a repressor of p21/Waf1 transcription. In epithelial cells of the intestine, the Myc-Miz1-p21/Waf1 cascade acts as a switch between differentiation and proliferation [97].

There are several other known genes, which show a de-creased expression level in Wntactivated cells. Examples are targets of the Jun (Ap1) family of transcription factors, which show decreased expression in Wnt-activated cells [99]. Many microarray screenings have been performed aiming to identify new target genes of the Wnt pathway $[99,100]$. Until now, only a limited number of candidate target genes have been confirmed and further characterised by experimental methods: conductin, cyclin D1, En-2, ID2, Mmp7, Myc, Nkd, Siamois, Tcf-1, Twin, Ubx, Xbra, Xnr3.

\section{Wnt signalling and disease}

\section{Metabolic disease}

The Wnt signalling pathway has a signifi cant role in cellular metabolism, especially in disorders that involve diabetes mellitus (DM). Type 2 DM represents at least $80 \%$ of all diabetics and is dramatically increasing in incidence as a result of changes in human behaviour and increased body mass index. Type 1 insulin-dependent DM accounts for only 5-10\% of all diabetics, but is increasing in adolescent minority groups. Yet the incidence of undiagnosed diabetes, impaired glucose tolerance and fluctuations in serum glucose in the young raises further concerns [101]. Individuals with impaired glucose tolerance have more than twice the risk for the development of diabetic complications than individuals with normal glucose tolerance. Regarding the vascular and nervous systems, patients with DM can develop severe neurological and vascular disease that can lead to an increased risk for cognitive decline. Diseases of the nervous system can become the most debilitating com-plications for DM and affect sensitive cognitive regions of the brain, such as the hippocampus that modulates memory function, resulting in significant functional impairment and dementia. Interestingly, the development of insulin resistance and the complications of DM in the nervous and vascular systems can be the result of cellular oxidative stress [102].

In patients with DM, elevated levels of ceruloplasmin are suggestive of increased reactive oxygen species and acute glucose fluctuations may promote oxidative stress [103]. Hyperglycaemia can lead to increased production of reactive oxygen species in endothelial cells, liver and pancreatic $\beta$-cells. Prolonged duration of hyperglycaemia is not necessary to lead to oxidative stress injury, since even short periods of hyperglycaemia generate reactive oxygen species, such as in vascular cells. Recent clinical correlates support these experimental studies to show that acute glucose swings in addition to chronic hyperglycaemia can trigger oxidative stress 
mechanisms during type $2 \mathrm{DM}$, illustrating the importance of therapeutic interventions during acute and sustained hyperglycaemic episodes [103]. The preservation of cellular energy reserves is dependent upon the maintenance of mitochondrial integrity during DM. For example, chronic exposure to elevated levels of free fatty acids can increase reactive oxygen species production in cells and has been shown to lead to mitochondrial DNA damage and impaired pancreatic $\beta$-cell function [104]. Insulin resistance in the elderly also has been associated with elevation in fat accumulation and altered mitochondrial oxidative and phosphorylation activity [105]. Current studies suggest that abnormalities in the Wnt signalling pathways, such as with transcription factor 7-like 2 gene (TCF7L2), may impart increased risk for type 2 DM in some populations [106] as well as have increased association with obesity [107]. Additional work has described the expression of $\mathrm{Wnt} 5 \mathrm{~b}$ in adipose tissue, the pancreas and the liver in diabetic patients, suggesting a potential regulation of adipose cell function.

Clinical observations in patients with coronary artery disease and the combined metabolic syndrome with hyper-tension, hyperlipidaemia and DM have observed impaired Wnt signalling through a missense mutation in LRP6 [108]. Experimental studies in mice with hyperglycaemia through a high-fat diet also demonstrate increased expression of some Wnt family members, such as WNT3A and WNT7A. In addition, intact WNT family members may offer glucose tolerance and increased insulin sensitivity as well as protect glomerular mesangial cells from elevated glucose-induced apoptosis. Animals that overexpressed WNT10Band were placed on a high-fat diet had a reduction in body weight, hyperinsulinaemia and triglyceride plasma levels and improved glucose homeostasis [109]. These clinical and experimental observations for the Wnt pathway in conditions associated with hyperglycaemia and DM suggest a potential protective cellular mechanism for WNT. Recent in vitrostudies demonstrate that the WNT1 protein is necessary and sufficient to provide cellular protection during elevated glucose exposure. Administration of exogenous Wnt1 protein can significantly prevent apoptotic endothelial cell injury during elevated glucose exposure. Interestingly, this protection by WNT1 can be regulated by the growth factor and cytokine EPO $[110,111]$. Through the Wnt pathway, EPO may offer an attractive therapy to maintain proper cellular metabolism and mitochondrial membrane potential during conditions of oxidative stress and DM.

EPO can at times enhance tissue function and is closely related to the maintenance of mitochondrial membrane potential $(\Delta \psi \mathrm{m})$. Loss of $\Delta \psi \mathrm{m}$ and the subsequent opening of the mitochondrial-permeability-transition-pore represent a significant determinant for cell injury and the subsequent induction of apoptosis. EPO has the capacity to prevent the depolarisation of the mitochondrial membrane that also affects the release of cytochrome c. With the Wnt pathway, EPO maintains the expression of Wntl during elevated glucose exposure and prevents loss of Wnt1 expression that would normally occur in the absence of EPO during elevated glucose. In addition, blockade of Wnt1 with a WNT1 antibody can neutralise the protective capacity of EPO, illustrating that WNT1 is a critical component in the cyto-protection of EPO during elevated glucose exposure [112].

\section{Neuronal disease}

The WNT pathway can influence both acute and chronic disease processes of the nervous system. For example, experimental models of behaviour suggest that the ability to tolerate stressful environments may be associated with the expression of WNT2. Other work suggests that loss of WNT signalling may contribute to retinal neurodegeneration as the progressive loss of photoreceptors during retinitis pigmentosa has been associated with increased secretion of the WNT inhibitory protein SFRP2.

Other reports have also demonstrated that a mutation in the membrane-type SFRP gene may be involved in retinal photoreceptor degeneration. In relation to cognitive function, WNT has been demonstrated in the brains of individuals affected by neuropsychiatric disorders. In models of front-temporal dementia, the WNT pathway can be upregulated early during the onset of the disease. It is conceivable that this increased expression of WNT may improve memory function similar to the way cognition is improved with agents such as lithium chloride that enhance WNT 
activity, as demonstrated in other work. Genetic analysis also suggests that LRP6 variants of the WNT pathway may be associated with late-onset Alzheimer's disease and that upregulation of the WNT pathway with agents such as cannabidiol may provide alternative treatments for Alzheimer's disease. Although it is unclear whether WNT expression has a direct role in the development of neuropsychiatric or dementia disorders, the WNT pathway has been tied to several of the pathological components of Alzheimer's disease $[113,114]$. The production of $\beta$-amyloid $(A \beta)$ peptide aggregates composed of 39-42 amino acid peptides and the accumulation of intracellular neurofibrillary tangles are considered to be two critical pathological mechanisms that lead to Alzheimer's disease. In Drosophila models of neurodegeneration, WNT can lead to neurofibrillary pathology. The proteolytic processing of amyloid precursor protein (APP) during Alzheimer's disease has been closely linked to the WNT pathway through presenilin 1 (PSEN1) and DVL1.

APP cleaves $\beta$-amyloid into products that include a 40 -residue peptide and a 42-residue peptide (A $\beta 1-42)$. How-ever, it is $A \beta 1-42$ that is considered to be the $\beta$-amyloid product that most directly leads to Alzheimer's disease and apoptotic injury. WNT may regulate APP isoform expression [115]. In addition, PSEN1 is required for the processing of APP and has been shown to downregulate WNT signalling and interact with $\beta$-catenin to promote its turnover. DVL1 also can regulate the $\alpha$-secretase cleavage of APP through protein kinase C/mitogen-activated protein kinase dependent pathways, increasing production of soluble APP [116].

Current studies also have examined the ability of WNT to directly reduce $\beta$-amyloid toxicity. Investigations with lovastatin as an extension of prior clinical work that suggests that a lower prevalence of Alzheimer's disease can occur during statin administration show that this agent can reduce $\beta$-amyloid production and cellular injury through increased $\beta$-catenin activity and the inhibition of GSK3B [117]. In addition, the pathways controlled by WNT1 appear to be critical for neuronal protection during $\beta$-amyloid exposure against genomic DNA degradation, membrane Psen exposure and microglial activation. The neuroprotective attributes of WNT1 against $\beta$ amyloid are lost during gene silencing of WNT1 protein expression. More importantly, WNT1 protection is dependent upon protein kinase B (AKT) activity and the inhibition of GSK3B with the cellular translocation of $\beta$-catenin to the nucleus.

\section{Cardiovascular disease}

During the process of wound healing in the heart, changes in components of the WNT-Fzd signalling pathway, such as WNT, FZD, DVL1, GSK3B, $\beta$-catenin and SFRP can occur. For example, during myoblast proliferation and migration following myocardial infarction, elevated expression of FZD genes including FZD1, 2, 5, 6, 7, 8and 10has been identified during heart remodelling. The overexpression of some FZD genes may be associated with reduction in infarct size and the prevention of cardiac rupture to improve cardiac function [118]. It is important to note that different members of the WNT family may contribute to distinct events during cardiac injury. Both WNT8Aand WNT10Bare upregulated following myocardial infarction while WNT7Bis downregulated to undetectable levels during this period [118]. Additional work also has demonstrated that $\beta$-catenin is translocated from the plasma membrane to the cytoplasm of endothelial cells following the expression of DVL during the phase of the neovascularisation after myocardial infarction. Furthermore, over-expression of antagonists of the WNT/FZD pathway can reverse the benefit of treatments such as ischaemic preconditioning and minimise $\beta$-catenin and AKT activity.

Furthermore, the expression of another WNT component, DVL1, appears to have a vital role during cardiac injury. The expression of DVL1mRNA and cytoplasmic Dvl1 protein is significantly enhanced within days in myo-fibroblasts, vascular endothelial cells and smooth muscle cells of newly formed and pre-existing blood vessels in the region of a myocardial infarction. 
In addition, mice without DVL1 demonstrate a benefit from pressure overload cardiac hypertrophy that is mediated through AKT and GSK3B [119]. In addition to FZD, DVL1and several WNT genes, other members of the WNT signalling cascade also appear to have relevant roles during myocardial injury. Other studies illustrate that cardiac rupture following myocardial infarction is correlated with decreased levels of $\beta$-catenin in cardiomyocytes. The lack of $\beta$-catenin in the adherence junctions of cardiomyocytes may lead to impaired structural integrity of the heart, since $\beta$-catenin may play a vital role in a structural adaptor protein linking cadherins to the actin cytoskeleton in cell-cell adhesion. Yet, the role of $\beta$-catenin during cardiac infarction is not entirely clear, since cytosolic $\beta$-catenin exists in vascular endothelial cells and smooth muscle cells that reside in the area of myocardial infarction [118]. Pathological cardiac hypertrophy also may be dependent upon modulation of the WNT pathway. Overexpression of Sfrp1 reduces infarct size and improves cardiac function in mice.

\section{WNT signalling and cancer}

WNT signalling pathway was first causally associated to carcinogenesis when it was found to be permanently activated in familial adenomatous polyposis (FAP) $[120,121]$ and spontaneous forms of colon cancer $[122,123]$. Chronic activation of WNT signalling in these intestinal tumours was the result of inactivating mutations in the APC locus and, to a much lesser extent, in $\beta$-catenin and AXIN2/conductin genes.

Mutations of APC in colorectal carcinoma (CRC) occur mostly in a mutation cluster region that is located approximately in the middle of the coding sequence. The mutations lead to frame shifts or stop codons, resulting in the generation of truncated APC proteins that lack several of the 20 -aminoacid repeats that interact with $\beta$-catenin and all the SAMP interaction domains for AXIN/conductin. It is thought that the resulting disturbance of the architecture of the $\beta$-catenin destruction complex is responsible for the stabilisation of $\beta$-catenin. Moreover, truncated APC also lacks several nuclear export sequences (NES) thought to be important for an APC-mediated export of $\beta$-catenin from the nucleus. In summary, APC mutations lead to accumulation of $\beta$-catenin and constitutive transcription of WNT target genes in the absence of exogenous WNT factors. It is not clear why CRC cells retain the truncated APC versions, i.e., why cancer-generating mutations do not completely abolish APC expression. Interestingly, a special form of attenuated FAP, in which patients develop much fewer polyps than in the classical FAP, is characterised by mutations that generate shorter APC proteins. This indicates that the truncated APC retains some function that is required for robust tumorigenesis. $\beta$-Catenin is mutated in up to $10 \%$ of all sporadic colon carcinomas by point mutations or in frame deletions of the serine and threonine residues that are phosphorylated by GSK3B. These mutations result in stabilisation of $\beta$-catenin and activation of WNT signal-ling. $\beta$-Catenin and APC mutations are mutually exclusive, possibly reflecting the fact that both components act on the same pathway [124].

Although it appears that mutations of WNT pathway components are sufficient to generate constitutive activation of WNT signalling in CRC, recent evidence suggests additional autocrine mechanisms involving stimulation of the pathway by secreted WNT proteins. Thus it was shown that colorectal cancer cells frequently express WNT, and that the WNT-pathway activity could be suppressed by treatment of the cells with SFRP, which interfere with WNT receptor binding. Importantly, SFRP genes are subject to inactivation by hypermethylation in the CRC cells, indicating an epigenetic mechanism that leads to a boost of the WNT signal [124].

After these seminal observations, a wide range of hu-man tumours have also been found to exhibit an aberrant activation of WNT signalling [125].

Interestingly, in contrast to colon malignancies, aberrant activation of WNT signalling in many of these tumours is not the result of mutations in the APC locus. Preferent mutations in $\beta$-catenin are found in liver cancer (hepato-cellular and hepatoblastoma), endometrial ovarian cancer, pilomatricoma skin cancer, prostate cancer, melanoma and Wilm's tumour [125]. AXIN1 mutations also occur in liver cancer and medulloblastoma. Other cancers present nuclear $\beta$-catenin 
translocation in the absence of mutation in APC, $\beta$-cateninor AXIN genes. Recent results indicate that this might occur through epigenetic inactivation of natural WNT pathway inhibitors [126].

Mutations of the AXIN gene and/or its loss of expression have also been found in colorectal cancers, oesophageal squamous cell carcinomas, hepatomas, hepatocellular carcinomas, medulloblastomas and endometrial ovarian carcinomas. Aberrant WNT signalling may play a role in lymphoid neoplasias, such as pre-B-cell leukaemia and myeloid leukaemia [124]. Interestingly, the overexpression of DKK1by myeloma cells is associated with the presence of lytic bone lesions in patients with multiple myeloma. Thus, deregulation of WNT/ $\beta$-catenin signalling may be involved in the development of many human malignancies. By contrast, WNT5A-mediated noncanonical pathway may function as a tumour suppressor, as WNT5Ais deleted or has reduced expression in haematopoietic tumours [124]. Mice that are hemizygous for WNT5A develop myeloid leukaemia and B-cell lymphomas [124].

Autocrine WNT stimulation has also been observed in other tumour cell types, in particular from breast and ovary. WNT signalling might also induce epigenetic changes through histone deacetylation. Expression of histone deacetylase 2 (HDAC2) was shown to be suppressed by APC, and inhibition of HDAC2 with low-molecular-mass inhibitors reduced intestinal polyp formation in the APC mutant Min mice [124].

The discovery of an aberrant WNT signalling linked to several cancers has fostered interest in the development of pharmacological WNT pathway inhibitors. However, despite the effort invested in this field, no specific pharmacological inhibitor of WNT signalling has been yet discovered [127]. In any case, a number of chemical compounds in use for treating other diseases, in particular non-steroidal inflammatory drugs (NSAIDs), and vitamin derivatives can also target the WNT signalling pathway [127].

It is generally assumed that inhibition of cyclooxygenase (COX) activity is the most important mechanism of action of traditional (aspirin, sulindac and indomethacin) and new-generation (celecoxib/Celebrex $^{\mathrm{TM}}$, Pfizer; rofecoxib/Vioxx ${ }^{\mathrm{TM}}$, Merck) NSAIDs. COX1 and 2 are central enzymes in the biosynthesis of prostaglandins [128]. Elevated production of prostaglandins in many cancers results in tumour growth, angiogenesis and metastasis [128]. In colon cancer, COX activity seems to be directly linked to WNT signalling. Prostaglandin activity can interfere with the cytoplasmic $\beta$-catenin degradation pathway, promoting the nuclear translocation of this protein $[129,130]$.

Vitamin A regulates cell growth and differentiation in a number of situations, and is crucial in embryonic development, reproduction, vision and immune responses. Vitamin A is metabolically converted into retinoids [131]. These compounds exert their biological functions by interaction with two families of nuclear receptors, retinoic acid receptor (RAR) and retinoid $\mathrm{X}$ receptor (RXR) [131]. In the nuclear compartment, both nuclear receptors can directly bind to $\beta$-catenin in competition with LEF/TCF factors, promoting a severe downregulation of WNT-dependent transcriptional activation $[132,133]$. Vitamin D is implicated in the regulation of calcium and phosphorus levels and is essential in the formation and maintenance of the skeleton. Vitamin D derivatives interact with the nuclear vitamin $\mathrm{D}$ receptor (VDR) to form a complex that can also bind to $\beta$-catenin $[134,135]$. In addition, active VDR transcription complex can efficiently promote the transcription of the E-cadherin (CDH1) gene, contributing to WNT signal inhibition by relocalisation of $\beta$-catenin to the cell membrane [134]. 


\section{Conclusions}

In the last years, an emerging concept suggesting that the origin of most cancers can be explained by invoking the existence of putative cancer stem cells has been the matter of intense debate [136].The most controversial point with this hypothesis lies in what exactly the term "cancer stem cells" is referring to. Now, it is assumed that a cancer stem cell is a any type of malignant cell after the acquisition of the basic properties commonly assigned to a normal stem cell, that is, the ability to undergo self-renewal and the ability to differentiate into different cell types [136].

This is a functional definition that can be equally ap-plied to different cell types. Thus, a series of genetic alterations can provide a normal stem cell with the ability to escape from growth restriction controls and to aberrantly expand and differentiate in multiple cells types giving raise to a tumour. In the same way, a transit-amplifying cell, i.e., a stem cell that has been committed to differentiate, but still retaining part of its differentiation potential, may also undergo genetic alterations leading to an unlimited proliferation and differentiation potential. Finally, a normal, fully differentiated, mature cell may also undergo a process of genetic and epigenetic alterations leading to physiological reversion that ultimately results in the acquisition of stem cell-like properties, escape from quiescent state and high proliferation rate. The final outcome in all cases is the generation of cancer stem cells.

At present, it is accepted that these cancer stem cells can be essential contributors to the driving force that is be-hind the most worrying phenomena observed in malignant tumours, i.e., relapse after treatment with chemotherapy or with surgical procedures and generation of metastasis in organs distant from the main focus of the tumour. Cancer stem cells are, thus, a subset of cells in the tumour with an unlimited capacity to proliferate and differentiate so that they are capable on its own to generate a whole tumour population. Current procedures for cancer treatment usually target the most abundant, actively proliferating, tumour cell populations, but not the basal cancer stem cells, which are in the origin of cancer development, expansion and metastasis. For the eradication of cancer, it will be necessary to design new pharmacological and surgical approaches to target cancer stem cells. However, to achieve these new approaches it will be necessary to define what a normal stem cell is (and by extension, what a cancer stem cell is) through the study of the molecular and physiological features that are involved in their peculiar behaviour in normal tissues and how their alteration can lead to cancer.

It is increasingly assumed that one the critical steps required to ignite carcinogenesis is the alteration of a number of key genes, involved in the signalling pathways that regulate stem cells proliferation and differentiation. Wnt signalling is essential during embryo development and in the maintenance of adult tissue homeostasis through the regulation of adult stem cell function. Therefore, Wnt path-way components are natural candidates as genetic factors that predispose to or trigger cancer. For example, it is well established that the alteration of APC is a key step (with the development of FAP) leading to colorectal cancer. Equally important, alteration of $\beta$-catenin is involved in a number of cancer types as liver, endometrial, ovarian, skin, prostate, melanoma and Wilm's tumour. Mutations of AXIN1, also involved in Wnt signalling, are linked to medulloblastoma. Finally, aberrant Wnt signalling may also play a key role in lymphoid neoplasias, such as pre-B-cell leukaemia or myeloid leukaemia.

Taken together, these data strongly support the idea that Wnt signalling is tightly associated with carcinogenesis and that components of this signalling pathway are adequate candidates as pharmacological targets. It is also tempting to speculate that aberrant Wnt signalling is involved in the generation of cancer stem cells from normal cells. However, it is clear that a better understanding of this signalling pathway and its connections with other important pathways is still necessary to develop efficient drugs of potential therapeutic application that can specifically target cancer stem cells. 
Acknowledgements. JE is a researcher hired by the Ramon y Cajal programme (Spanish Government) and supported by the Spanish Ministry of Science and Innovation (SAF2008-00609). MBC is hired through the research support programme from Instituto de Salud Car-los III (Spanish Government). SDP is hired through the Isidro Parga Pondal programme by Xunta de Galicia (Spain). VMV is supported by A Coruña University Hospital Foundation.

Conflict of interest. The authors declare that they have no conflict of interest relating to the publication of this manuscript.

\section{References}

1. Nusse R (2001) An ancient cluster of Wnt paralogues. Trends Genet 17:443

2. Grigoryan T, Wend P, Klaus A, Birchmeier W (2008) Deciphering the function of canonical Wnt signals in development and disease: conditional loss- and gain-of-function mutations of beta-catenin in mice. Genes Dev 22:2308-2341

3. Huang H, He X (2008) Wnt/beta-catenin signaling: new (and old) players and new insights. Curr Opin Cell Biol 20:119-125

4. Ling L, Nurcombe V, Cool SM (2008) Wnt signaling controls the fate of mesenchymal stem cells. Gene 433:1-7

5. $\quad$ Nusse R (2008) Wnt signaling and stem cell control. Cell Res 18:523-527

6. Mosimann C, Hausmann G, Basler K (2009) Beta-catenin hits chromatin: regulation of Wnt target gene activation. Nat Rev Mol Cell Biol 10:276-286

7. $\quad$ Li F, Chong ZZ, Maiese K (2005) Vital elements of the Wnt-frizzled signalling pathway in the nervous system. Curr Neurovasc Res 2:331-340

8. Li F, Chong ZZ, Maiese K (2006) Winding through the WNT pathway during cellular development and demise. Histol Histopathol 21:103-124

9. Miller JR (2002) The Wnts. Genome Biol 3:reviews3001.1-3001.1510. Reichsman F, Smith L, Cumberledge S (1996) Glycosaminoglycans can modulate extracellular localization of the wingless protein and promote signal transduction. J Cell Biol 135:819-827

10. Shibamoto S, Higano K, Takada R et al (1998) Cytoskeletal reorganization by soluble Wnt-3a protein signalling. Genes Cells 3:659-670

11. van den Heuvel M, Nusse R, Johnston P, Lawrence PA (1989) Distribution of the wingless gene product in Drosophila embryos: a protein involved in cell-cell communication. Cell 59:739-749

12. Bejsovec A, Wieschaus E (1995) Signalling activities of the Drosophila wingless gene are separately mutable and appear to be transduced at the cell surface. Genetics 139:309-320

13. Moline MM, Southern C, Bejsovec A (1999) Directionality of wingless protein transport influences epidermal patterning in the Drosophila embryo. Development 126:4375-4384

14. Dubois L, Lecourtois M, Alexandre C et al (2001) Regulated endocytic routing modulates wingless signalling in Drosophila embryos. Cell 105:613-624

15. Greco V, Hannus M, Eaton S (2001) Argosomes: a potential vehicle for the spread of morphogens through epithelia. Cell 106:633-645

16. Simmonds AJ, dosSantos G, Livne-Bar I, Krause HM (2001) Apical localization of wingless transcripts is required for wingless signalling. Cell 105:197-207

17. Wilkie GS, Davis I (2001) Drosophila wingless and pair-rule transcripts localize apically by dyneinmediated transport of RNA particles. Cell 105:209-219

18. Axelrod JD, Miller JR, Shulman JM et al (1998) Differential recruitment of Dishevelled provides signalling specificity in the planar cell polarity and Wingless signalling pathways. Genes Dev 12:2610 2622

19. Boutros M, Paricio N, Strutt DI, Mlodzik M (1998) Dishevelled activates JNK and discriminates between JNK pathways in planar polarity and wingless signalling. Cell 94:109-118

20. Itoh K, Brott BK, Bae GU, Ratcliffe MJ, Sokol SY (2005) Nuclear localization is required for Dishevelled function in Wnt/beta-catenin signalling. J Biol 4:3

21. Patapoutian A, Reichardt LF (2000) Roles of Wnt proteins in neural development and maintenance. Curr Opin Neurobiol 10:392-399

22. Seifert JR, Mlodzik M (2006) Frizzled/PCP signalling: a conserved mechanism regulating cell polarity and directed motility. Nat Rev Genet 8:126-138

23. Ma L, Wang HY (2006) Suppression of cyclic GMP-dependent protein kinase is essential to the Wnt/GMP/Ca2+ pathway. J Biol Chem 281:30990-31001

24. Schulte G, Bryja V (2007) The frizzled family of unconventional G-protein-coupled receptors. Trends Pharmacol Sci 28:518-525 
25. Foord SM, Bonner TI, Neubig RR et al (2005) International union of pharmacology. XLVI. G proteincoupled receptor list. Pharmacol Rev 57:279-288

26. Melkonyan HS, Chang WC, Shapiro JP et al (1997) SARPs: a family of secreted apoptosis-related proteins. Proc Natl Acad Sci USA 94:13636-13641

27. Wilson C, Goberdhan DC, Steller H (1993) Dror, a potential neurotrophic receptor gene, encodes a Drosophila homolog of the vertebrate Ror family of Trk-related receptor tyrosine kinases. Proc Natl Acad Sci USA 90:7109-7113

28. Song L, Fricker LD (1997) Cloning and expression of human carboxypeptidase Z, a novel metallocarboxypeptidase. J Biol Chem 272:10543-10550

29. Yan W, Sheng N, Seto M, Morser J, Wu Q (1999) Corin, a mosaic transmembrane serine protease encoded by a novel cDNA from human heart. J Biol Chem 274:14926-14935

30. Wehrli M, Dougan ST, Caldwell K et al (2000) Arrow encodes an LDL-receptor-related protein essential for Wingless signalling. Nature 407:527-530

31. Mao J, Wang J, Liu B et al (2001) Low-density lipoprotein receptor-related protein-5 binds to Axin and regulates the canonical Wnt signalling pathway. Mol Cell 7:801-809

32. Tolwinski NS, Wehrli M, Rives A et al (2003) Wg/Wnt signal can be transmitted through arrow/LRP5, 6 and Axin independently of Zw3/Gsk3-beta activity. Dev Cell 4:407-418

33. Bejsovec A (2005) Wnt pathway activation: new relations and locations. Cell 120:11-14

34. Lu W, Yamamoto V, Ortega B, Baltimore D (2004) Mammalian Ryk is a Wnt coreceptor required for stimulation of neurite outgrowth. Cell 119:97-108

35. Ching W, Nusse R (2006) A dedicated Wnt secretion factor. Cell 125:432-433

36. Bänziger C, Soldini D, Schütt C et al (2006) Wnt-less, a conserved membrane protein dedicated to the secretion of Wnt proteins from signalling cells. Cell 125:509-522

37. Bartscherer K, Pelte N, Ingelfinger D, Boutros M (2006) Secretion of Wnt ligands requires Evi, a conserved transmembrane protein. Cell 125:523-533

38. Vergés M, Luton F, Gruber C et al (2004) The mammalian retromer regulates transcytosis of the polymeric immunoglobin receptor. Nat Cell Biol 6:763-769

39. Coudreuse DY, Roel G, Betist MC et al (2006) Wnt gradient formation requires retromer function in Wnt-producing cells. Science 312:921-924

40. Hsieh JC, Rattner A, Smallwood PM, Nathans J (1999) Biochemical characterization of Wnt-frizzled interactions using a soluble, biologically active vertebrate Wnt protein. Proc Natl Acad Sci USA 382:225-230

41. He X, Semenov M, Tamai K, Zeng X (2004) LDL receptor-related proteins 5 and 6 in Wnt/beta-catenin signalling: arrows point the way. Development 131:1663-1677

42. Zeng X, Tamai K, Doble B et al (2005) A dual-kinase mechanism for Wnt co-receptor phosphorylation and activation. Nature 438: 873-877

43. Forrester WC (2002) The Ror receptor tyrosine kinase family. Cell Mol Life Sci 59:83-96

44. Oishi I, Suzuki H, Onishi N et al (2003) The receptor tyrosine kinase Ror2 is involved in non-canonical Wnt5a/JNK signalling pathway. Genes Cells 8:645-654

45. Mikels AJ, Nusse R (2006) Purified Wnt5a protein activates or inhibits beta-catenin-TCF signalling depending on receptor context. PLoS Biol 4:e115

46. Moon RT, Kimelman D (1998) From cortical rotation to organizer gene expression: toward a molecular explanation of axis specification in Xenopus. BioEssays 20:536-545

47. Sumanas S, Strege P, Heasman J, Ekker SC (2000) The putative wnt receptor Xenopus frizzled-7 functions upstream of beta-catenin in vertebrate dorsoventral mesoderm patterning. Development 127:1981-1990

48. Reya T, Clevers H (2005) Wnt signalling in stem cells and cancer. Nature 434:843-850

49. Korinek V, Barker N, Moerer P et al (1998) Depletion of epithelial stem-cell compartments in the small intestine of mice lacking Tcf-4. Nat Genet 19:379-383

50. Kim KA, Kakitani M, Zhao J et al (2005) Mitogenic influence of human R-spondin1 on the intestinal epithelium. Science 309:1256-1259

51. van Genderen C, Okamura RM, Farinas I et al (1994) Development of several organs that require inductive epithelial-mesenchymal interactions is impaired in LEF-1-deficient mice. Genes Dev 8:26912703

52. Alonso L, Fuchs E (2003) Stem cells in the skin: waste not, Wnt not. Genes Dev 17:1189-1200

53. Huelsken J, Vogel R, Erdmann B et al (2001) beta-Catenin controls hair follicle morphogenesis and stem cell differentiation in the skin. Cell 105:533-545

54. Lowry WE, Blanpain C, Nowak JA et al (2005) Defining the impact of beta-catenin/Tcf transactivation on epithelial stem cells. Genes Dev 19:1596-1611

55. Reya T, Duncan AW, Ailles L et al (2003) A role for Wnt signalling in self-renewal of haematopoietic stem cells. Nature 423:409-414

56. Kishida M, Hino SI, Michiue T et al (2001) Synergistic activation of the Wnt signalling pathway by Dvl and casein kinase Iepsilon. J Biol Chem 276:33147-33155 
57. Ishitani T, Ninomiya-Tsuji J, Matsumoto K (2003) Regulation of lymphoid enhancer factor 1/T-cell factor by mitogen-activated protein kinase-related Nemo-like kinase-dependent phosphorylation in Wnt/beta-catenin signalling. Mol Cell Biol 23:1379-1389

58. Graham NA, Asthagiri AR (2004) Epidermal growth factor-mediated T-cell factor/lymphoid enhancer factor transcriptional activity is essential but not sufficient for cell cycle progression in nontransformed mammary epithelial cells. J Biol Chem 279:23517-23524

59. Li F, Chong ZZ, Maiese K (2006) Microglial integrity is maintained by erythropoietin through integration of Akt and its substrates of glycogen synthase kinase-3beta, beta-catenin, and nuclear factorkappaB. Curr Neurovasc Res 3:187-201

60. Chen AE, Ginty DD, Fan CM (2005) Protein kinase A signalling via CREB controls myogenesis induced by Wnt proteins. Nature 433:317-322

61. D'Amico M, Hulit J, Amanatullah DF et al (2000) The integrin-linked kinase regulates the cyclin D1 gene through glycogen synthase kinase 3 beta and cAMP-responsive element-binding protein-dependent pathways. J Biol Chem 275:32649-32657

62. Kinoshita N, lioka H, Miyakoshi A, Ueno N (2003) PKC delta is essential for Dishevelled function in a noncanonical Wnt pathway that regulates Xenopus convergent extension movements. Genes Dev 17:1663-1676

63. Tu X, Joeng KS, Nakayama KI et al (2007) Non-canonical Wnt signalling through G protein-linked PKC delta activation promotes bone formation. Dev Cell 12:113-127

64. Ouko L, Ziegler TR, Gu LH et al (2004) Wnt11 signalling promotes proliferation, transformation, and migration of IEC6 intestinal epithelial cells. J Biol Chem 279:26707-26715

65. Kremenevskaja N, von Wasielewski R, Rao AS et al (2005) Wnt-5a has tumour suppressor activity in thyroid carcinoma. Oncogene 24: 2144-2154

66. Dejmek J, Safholm A, Kamp Nielsen C et al (2006) Wnt-5a/Ca2+-induced NFAT activity is counteracted by Wnt-5a/Yes-Cdc42-casein kinase 1 signalling in human mammary epithelial cells. Mol Cell Biol 26:6024-6036

67. Safholm A, Leandersson K, Dejmek J et al (2006) A formylated hexapeptide ligand mimics the ability of Wnt-5a to impair migration of human breast epithelial cells. J Biol Chem 281:2740-2749

68. Westfall TA, Brimeyer R, Twedt J et al (2003) Wnt-5/pipetail functions in vertebrate axis formation as a negative regulator of Wnt/beta-catenin activity. J Cell Biol 162:889-898

69. Ishitani T, Ninomiya-Tsuji J, Nagai S et al (1999) The TAK1-NLK-MAPK-related pathway antagonizes signalling between beta-catenin and transcription factor TCF. Nature 399:798-802

70. Garriock RJ, Krieg PA (2007) Wnt11-R signalling regulates a calcium sensitive EMT event essential for dorsal fin development of Xenopus. Dev Biol 304:127-140

71. De Calisto J, Araya C, Marchant L et al (2005) Essential role of non-canonical Wnt signalling in neural crest migration. Development 132:2587-2597

72. Matsui T, Raya A, Kawakami Y et al (2005) Noncanonical Wnt signalling regulates midline convergence of organ primordial during zebrafish development. Genes Dev 19:164-175

73. Jenny A, Reynolds-Kenneally J, Das G et al (2005) Diego and Prickle regulate Frizzled planar cell polarity signalling by competing for Dishevelled binding. Nat Cell Biol 7:691-697

74. Strutt D (2003) Frizzled signalling and cell polarisation in Drosophila and vertebrates. Development 130:4501-4513

75. Hikasa H, Shibata M, Hiratami I, Taira M (2002) The Xenopus receptor tyrosine kinase Xror2 modulates morphogenetic movements of the axial mesoderm and neuroectoderm via Wnt signalling. Development 129: 5227-5239

76. Wu C, Zeng Q, Blumer KJ, Muslin AJ (2000) RGS proteins inhibit Xwnt-8 signalling in Xenopus embryonic development. Development 127:2773-2784

77. Liu T, DeCostanzo AJ, Liu X et al (2001) G protein signalling from activated rat frizzled-1 to the betacatenin-Lef-Tcf pathway. Science 292:1718-1722

78. Katanaev VL, Ponzielli R, Semeriva M, Tomlinson A (2005) Trimeric G protein-dependent frizzled signalling in Drosophila. Cell 120:111-122

79. Park E, Kim GH, Choi SC, Han JK (2006) Role of PKA as a negative regulator of PCP signalling pathway during Xenopus gastrulation movements. Dev Biol 292:344-357

80. Hoang B, Moos M Jr, Vukicevic S, Luyten FP (1996) Primary structure and tissue distribution of FRZB, a novel protein related to Drosophila frizzled, suggest a role in skeletal morphogenesis. J Biol Chem 271:26131-26137

81. Rattner A, Hsieh JC, Smallwood PM et al (1997) A family of secreted proteins contains homology to the cysteinerich ligand-binding domain of frizzled receptors. Proc Natl Acad Sci USA 94:2859-2863

82. Bafico A, Gazit A, Pramila T et al (1999) Interaction of frizzled related protein (FRP) with Wnt ligands and the frizzled receptor suggests alternative mechanisms for FRP inhibition of Wnt signalling. J Biol Chem 274:16180-16187

83. Lin K, Wang S, Julius MA et al (1997) The cysteine-rich frizzled domain of Frzb-1 is required and sufficient for modulation of Wnt signalling. Proc Natl Acad Sci USA 94:11196-11200 
84. Wawrzak D, Metioui M, Willems E et al (2007) Wnt3a binds to several sFRPs in the nanomolar range. Biochem Biophys Res Commun 357:1119-1123

85. Wu W, Glinka A, Delius H, Niehrs C (2000) Mutual antagonism between dickkopf1 and dick kopf2 regulates Wnt/beta-catenin signalling. Curr Biol 10:1611-1614

86. Lin X (2004) Functions of heparan sulfate proteoglycans in cell signalling during development. Development 131:6009-6021

87. Fre S, Vignjevic D, Schoumacher M et al (2008) Epithelial morphogenesis and intestinal cancer: new insights in signalling mechanisms. Cancer Res 100:85-111

88. Piters E, Boudin E, Hul WV (2008) Wnt signalling: a win for bone. Arch Biochem Biophys 473:112116

89. Hwang SG, Yu SS, Lee SW, Chun JS (2005) Wnt-3a regulates chondrocyte differentiation via cJun/AP-1 pathway. FEBS Lett 579:4837-4842

90. Guo X, Day TF, Jiang X et al (2004) Wnt/beta-catenin signalling is sufficient and necessary for synovial joint formation. Genes Dev 18:2404-2417

91. Hu H, Hilton MJ, Tu X et al (2005) Sequential roles of Hedgehog and Wnt signalling in osteoblast development. Development 132:49-60

92. Huelsken J, Birchmeier W (2001) New aspects of Wnt signalling pathways in higher vertebrates. Curr Opin Genet Dev 11:547-553

93. Nusse R (1999) Wnt targets. Repression and activation. Trends Genet 15:1-3

94. Giles RH, van Es JH, Clevers H (2003) Caught up in a Wnt storm: Wnt signalling in cancer. Biochim Biophys Acta 1653:1-24

95. Howe LR, Crawford HC, Subbaramaiah K et al (2001) PEA3 is up-regulated in response to Wnt1 and activates the expression of cyclooxygenase-2. J Biol Chem 276:20108-20115

96. van de Wetering M, Sancho E, Verweij C et al (2002) The beta-catenin/TCF-4 complex imposes a crypt progenitor phenotype on colorectal cancer cells. Cell 111:241-250

97. Wu S, Cetinkaya C, Munoz-Alonso MJLN et al (2003) Myc represses differentiation-induced p21CIP1 expression via Miz-1-dependent interaction with the p21 core promoter. Oncogene 22:351-360

98. Tice DA, Soloviev I, Polakis P (2002) Activation of the Wnt pathway interferes with serum response element-driven transcription of immediate early genes. J Biol Chem 277:6118-6123

99. Staal FJ, Weerkamp F, Baert MR et al (2004) Wnt target genes identified by DNA microarrays in immature CD34+ thymocytes regulate proliferation and cell adhesion. J Immunol 172:1099-1108

100. Jacobson AM, Musen G, Ryan CM et al (2007) Long-term effect of diabetes and its treatment on cognitive function. N Engl J Med 356:1842-1852

101. Maiese K, Chong ZZ, Shang YC (2007) Mechanistic insights into diabetes mellitus and oxidative stress. Curr Med Chem 14:1689-1699

102. Monnier L, Mas E, Ginet $\mathrm{C}$ et al (2006) Activation of oxidative stress by acute glucose fluctuations compared with sustained chronic hyperglycemia in patients with type 2 diabetes. JAMA 295:16811687

103. Rachek LI, Thornley NP, Grishko VI et al (2006) Protection of INS-1 cells from free fatty acid-induced apoptosis by targeting hOGG1 to mitochondria. Diabetes 55:1022-1028

104. Pospisilik JA, Knauf C, Joza N et al (2007) Targeted deletion of AIF decreases mitochondrial oxidative phosphorylation and protects from obesity and diabetes. Cell 131:476-491

105. Lehman DM, Hunt KJ, Leach RJ et al (2007) Haplotypes of transcription factor 7-like 2 (TC-F7L2) gene and its upstream region are associated with type 2 diabetes and age of onset in Mexican Americans. Diabetes 56:389-393

106. Guo YF, Xiong DH, Shen H et al (2006) Polymorphisms of the low-density lipoprotein receptor-related protein 5 (LRP5) gene are associated with obesity phenotypes in a large family-based association study. J Med Genet 43:798-803

107. Mani A, Radhakrishnan J, Wang H et al (2007) LRP6 mutation in a family with early coronary disease and metabolic risk factors. Science 315:1278-1282

108. Aslanidi G, Kroutov V, Philipsberg G et al (2007) Ectopic expression of Wnt10b decreases adiposity and improves glucose homeostasis in obese rats. Am J Physiol Endocrinol Metab 293: E726-E736

109. Maiese K, Li F, Chong ZZ (2004) Erythropoietin in the brain: can the promise to protect be fulfilled? Trends Pharmacol Sci 25:577-583

110. Maiese K, Li F, Chong ZZ (2005) New avenues of exploration for erythropoietin. JAMA 293:90-95

111. Chong ZZ, Shang YC, Maiese K (2007) Vascular injury during elevated glucose can be mitigated by erythropoietin and Wnt signalling. Curr Neurovasc Res 4:194-204

112. Li F, Chong ZZ, Maiese K (2005) Vital elements of the Wnt-frizzled signalling pathway in the nervous system. Curr Neurovasc Res 2:331-340

113. Li F, Chong ZZ, Maiese K (2006) Winding through the WNT pathway during cellular development and demise. Histol Histopathol 21:103-124

114. Morin PJ, Medina M, Semenov M et al (2004) Wnt-1 expression in PC12 cells induces exon 15 deletion and expression of L-APP. Neurobiol Dis 16:59-67 
115. Mudher A, Chapman S, Richardson J et al (2001) Dishevelled regulates the metabolism of amyloid precursor protein via protein kinase $\mathrm{C} /$ mitogen activated protein kinase and c-Jun terminal kinase. $\mathrm{J}$ Neurosci 21:4987-4995

116. Salins P, Shawesh S, He Y et al (2007) Lovastatin protects human neurons against Abeta-induced toxicity and causes activation of beta-catenin-TCF/LEF signalling. Neurosci Lett 412:211-216

117. Barandon L, Couffinhal T, Ezan J et al (2003) Reduction of infarct size and prevention of cardiac rupture in transgenic mice overexpressing FrzA. Circulation 108:2282-2289

118. van de Schans VA, van den Borne SW, Strzelecka AE et al (2007) Interruption of Wnt signalling attenuates the onset of pressure overload-induced cardiac hypertrophy. Hypertension 49:473-480

119. Kinzler KW, Nilbert MC, Su LK et al (1991) Identification of FAP locus genes from chromosome 5q21. Science 253:661-665

120. Nishisho I, Nakamura Y, Miyoshi Y et al (1991) Mutations of chromosome 5q21 genes in FAP and colorectal cancer patients. Science 253:665-669

121. Korinek V, Barker N, Morin PJ et al (1997) Constitutive transcriptional activation by a beta-catenin-Tcf complex in APC- -1 - colon carcinoma. Science 275:1784-1787

122. Morin PJ, Sparks AB, Korinek V et al (1997) Activation of beta-catenin-Tcf signalling in colon cancer by mutations in beta-catenin or APC. Science 275:1787-1790

123. Liang H, Chen Q, Coles AH et al (2003) Wnt5a inhibits B cell proliferation and functions as a tumour suppressor in hematopoietic tissue. Cancer Cell 4:349-360

124. Polakis P (2000) Wnt signalling and cancer. Genes Dev 14:1837-1851

125. Aguilera O, Munoz A, Esteller M, Fraga MF (2007) Epigenetic alterations of the Wnt/beta-catenin pathway in human disease. Endocr Metab Immune Disord Drug Targets 7:13-21

126. Barker N, Clevers H (2006) Mining the Wnt pathway for cancer therapeutics. Nat Rev Drug Discov 5:997-1014

127. Thun MJ, Henley SJ, Patrono C (2002) Nonsteroidal anti-inflammatory drugs as anticancer agents: mechanistic, pharmacologic, and clinical issues. J Natl Cancer Inst 94:252-266

128. Castellone MD, Teramoto H, Williams BO et al (2005) Prostaglandin E2 promotes colon cancer cell growth through a Gs-axin-beta-catenin signalling axis. Science 310:1504-1510

129. Shao J, Jung C, Liu C, Sheng H (2005) Prostaglandin E2 Stimulates the beta-catenin/T cell factordependent transcription in colon cancer. J Biol Chem 280:26565-26572

130. Soprano DR, Qin P, Soprano KJ (2004) Retinoic acid receptors and cancers. Annu Rev Nutr 24:201221

131. Shah S, Hecht A, Pestell R, Byers SW (2003) Trans-repression of beta-catenin activity by nuclear receptors. J Biol Chem 278:48137-48145

132. Xiao JH, Ghosn C, Hinchman C et al (2003) Adenomatous polyposis coli (APC)-independent regulation of beta-catenin degradation via a retinoid X receptor-mediated pathway. J Biol Chem 278:29954-29962

133. Palmer HG, Larriba MJ, Garcia JM et al (2004) The transcription factor SNAIL represses vitamin D receptor expression and responsiveness in human colon cancer. Nat Med 10:917-919

134. Shah S, Islam MN, Dakshanamurthy S et al (2006) The molecular basis of vitamin D receptor and betacatenin crossregulation. Mol Cell 21:799-809

135. Jordan CT (2009) Cancer stem cells: controversial or just misunderstood? Cell Stem Cell 4:203-205 